\title{
Impact of windward inlet opening positions on fluctuation characteristics of wind-driven natural cross-ventilation in an isolated house using LES
}

\author{
Sherzad Hawendi*, Shian Gao \\ Department of Engineering, University of Leicester, LE1 7RH, United Kingdom \\ * Corresponding author: phone: +44(0)116 252 2874; fax: +44(0)116 252 2525; e-mail: sh567@ le.ac.uk.
}

\begin{abstract}
This paper presents a computational fluid dynamics (CFD) simulation of coupled outdoor wind flow and indoor air flow in the investigation on the horizontal positions of openings on the fluctuation of cross-ventilation and flow field inside an isolated family house. Two inlet-opening positions located at the same height are used to investigate the impact of the position of windward inlet openings on ventilation rate and flow field inside the building. Due to unsteady flow and high turbulence near the openings, the study employed the large eddy simulation (LES) with the dynamic Smagorinsky subgrid-scale model techniques, with the CFD simulations being validated against data from available wind tunnel experiments. The study showed that the rate of ventilation through openings located near the centre of the building is higher and more steady than the flow rate of openings located near the sides of the building.
\end{abstract}

Keywords: CFD; Windward inlet opening positions; Cross ventilation; LES; Ventilation rate NOMENCLATURE
$A$
Area $\left(\mathrm{m}^{2}\right)$
$C_{s}$
Dynamic Smagorinsky coefficient
$C_{p}$ Dimensionless pressure coefficient $\left(\left(P-P_{o}\right) / 0.5 \rho U^{2}{ }_{r e f}\right)$
Height of the building (m) 


$\begin{array}{ll}I_{u} & \text { Turbulence intensity }\left(\mathrm{u}_{\mathrm{rmm}} / \mathrm{u}_{\text {mean }}\right) \\ k_{\text {res }} & \text { Resolved turbulent kinetic energy }\left(\mathrm{m}^{2} / \mathrm{s}^{2}\right) \\ k_{\text {num }} & \text { Numerical dissipation turbulent kinetic energy }\left(\mathrm{m}^{2} / \mathrm{s}^{2}\right) \\ k_{s g s} & \text { Subgrid scale turbulent kinetic energy }\left(\mathrm{m}^{2} / \mathrm{s}^{2}\right) \\ k_{t} & \text { Total turbulent kinetic energy }\left(\mathrm{m}^{2} / \mathrm{s}^{2}\right) \\ L & \text { Length of the domain }(\mathrm{m}) \\ R e & \text { Average Reynolds number based on the building heigh } \\ P_{o} & \text { Reference pressure }(\mathrm{Pa}) \\ Q^{*} & \text { Dimensionless ventilation rate } \\ u_{\tau} & \text { Friction velocity }(\mathrm{m} / \mathrm{s}) \\ U(y) & \text { Mean velocity at height y above the ground }(\mathrm{m} / \mathrm{s}) \\ U_{r e f} & \text { External wind speed at the building height }(\mathrm{m} / \mathrm{s}) \\ V & \text { Volume of the computational cell } \\ y^{+} & \text {Dimensionless wall }(\text { normal }) \text { distance, } \mathrm{u}_{\tau} \mathrm{y} / \mathrm{v} \\ y_{o} & \text { Aerodynamics roughness length }(\mathrm{m}) \\ & \\ \text { Greek symbols } & \text { Rate of dissipation of turbulent kinetic energy }\left(\mathrm{m}^{2} / \mathrm{s}^{3}\right) \\ \varepsilon & \text { Von Karman constant } \\ \kappa & \text { Dynamic viscosity }(\mathrm{kg} / \mathrm{m} . \mathrm{s}) \\ \mu & \text { Turbulent viscosity }(\mathrm{Pa} . \mathrm{s}) \\ \mu_{t} & \text { Kinematic viscosity }\left(\mathrm{m}^{2} / \mathrm{s}\right) \\ v & \text { Density }\left(\mathrm{kg} / \mathrm{m}^{3}\right) \\ \rho & \text { Rate of strain tensor } \\ \bar{S}_{i j} & \text { Subgrid-scale stress } \\ \tau_{i j} & \text { Volume of the computational cell } \\ \Delta & \end{array}$

\section{Introduction}

Natural ventilation is important because it can provide thermal comfort inside buildings for residents by supplying fresh air without fans. For warm and hot climates, it can help meet a building's cooling requirements without using mechanical air conditioning systems, which make up a large fraction of a building's total energy use. In addition, it is an important factor in the development of the sustainable sector. Successful ventilation is determined as having high thermal comfort, lower contaminant concentrations. adequate fresh air for ventilated spaces and having little or no energy use for active heating, ventilation and air conditioning (HVAC) [1]. Natural ventilation is the use of natural forces, including both wind and thermal buoyancy, to 
regulate a building's indoor climate. As the weather outside often changes, it can be difficult to maintain stable conditions inside a building [2]. As mentioned in previous studies, there are a number of requirements which need to be established for this type of ventilation due to limited natural driving forces such as internal spaces, and the size and placement of ventilation openings in the building, internal heat load, and the surroundings [3]. There are three basic types of ventilation, depending on the position of the openings in the outer walls: single-side ventilation, cross ventilation and stack ventilation.

Studying natural ventilation by experimental methods has been tested in many types of buildings for numerous reasons, though usually through two principal, though complicated and expensive, methods during research: wind tunnels [3-11] and field measurements for existing buildings [12-14]. Karava et al. [11] tested six cases of inlet-outlet vertical opening positions on opposite walls and four cases on adjacent walls in natural cross ventilation; they found that the inlet-to-outlet ratio and the relative location of openings on a building's façade are important parameters that must be considered in addition to wall porosity. Tominaga et al. [9] analysed five configurations of inlet-outlet vertical configuration on field flow and dispersion of contaminants in cross-ventilated buildings and their results provide new insights into the flow and dispersion processes inside naturally cross-ventilated buildings, and can be used in computational fluid dynamics (CFD) validations of flow and dispersion.

Due to providing many details of airflow both inside and outside buildings in both a steady and a transient manner, the CFD has seen widespread use in predicting ventilation performance. Reynolds Averaged Navier-Stokes (RANS) is frequently used in turbulence modelling [8, 1222]. This approach may provide appropriate cross-ventilation flow characteristics with a relatively economical computational cost, but such models are less satisfactory in their description of turbulent features within and around buildings. An alternative approach, such as 
large eddy simulation (LES), can predict information on flow structure, including turbulence statistics, and describe the flow field variation over a given period of time. Jiang and Chen [23] performed cross- and single-sided ventilation of a cube building with two openings using two subgrid-scale models, namely the Smagorinsky subgrid-scale (SS) and filtered dynamic subgridscale (FDS) models. Subsequently, Jiang and Chen [24] focused on the impact of the fluctuation of wind-driven, natural cross ventilation in four apartments. Their results showed the important role of the fluctuating flow field in determining an accurate ventilation rate through the openings. In 2003, Jiang et al. [25] concluded that the two models, SS and FDS, provide almost the same results when compared with those of physical wind tunnel measurements, and explained that most of the energy of the airflow around a building is contained in large eddies, which are known to have a greater effect than small eddies.

Unsteady cross-ventilation flow modelling was performed by $\mathrm{Hu}$ et al. [26] on a small building using a sub-grid Smagorinsky model with constant $C_{s}=0.12$ applied to it. Driver domain, which was proposed by Lund et al. [27], was used to generate flow fluctuations. Their results showed that the standard deviation of the fluctuation flow rate is small when the wind direction is normal to the aperture.

Chu and Chiang [28] investigated the influences of internal resistance on wind-driven crossventilation by LES and wind tunnel experiments. The ventilation rate in a building with a rectangular plate inside was measured, together with the impact of plate size and location, on the external pressure and ventilation rate. The results showed that the resistance factor is a function of internal blockage ratio and location, but is independent of external wind speed, building size and opening configuration. Furthermore LES and wind tunnel experiments were used by the same authors [29] to study the effect of building length on natural ventilation rate. The numerical results revealed that ventilation rate decreases as building length increases due to a reduction in 
the pressure difference. The other reason for the decline in ventilation rate was that the internal friction from turbulent flow caused a 'sluggish zone' with a low wind speed inside the building when the building length was greater than five times its height. Tuan et al. [30] used LES to investigate the impact of the downstream construction of terraced houses on nearby, upstream houses, and the flow patterns inside them. Recently, an in-depth comparison between five different steady RANS models and LES has been performed by van Hooff et al. [31] to determine which CFD model is the most suitable for cross-ventilation flows in a generic, isolated building. The study shows that the five steady RANS models failed to reproduce any turbulent kinetic energy, whilst LES shows a better reproduction of velocity, turbulent kinetic energy, and volume flow rate parameters.

In summary, the majority of previous studies have investigated only the time-averaged ventilation rates using the steady RANS method by testing different heights of the opening positions, whereas other studies have employed transient models to focus on fluctuating ventilation rates of openings located at the middle of the building. There is limited knowledge about the impact of turbulence and fluctuation of flow from the windward openings of the building at different horizontal locations that cannot be predicted by steady methods. In addition, the position of windward inlet openings in buildings has a major role in natural ventilation processes and not only changes the appearance of the building, but can also influence the efficiency of natural ventilation and thermal comfort. Therefore, this paper will focus on investigating the impact of the horizontal position of the windward inlet openings on the fluctuation of the cross ventilation and flow field inside the building using the LES method.

\section{Building geometry and study cases}


A low-rise, isolated building model in cross-turbulent flow was considered for the computational analysis of wind-induced natural ventilation. Figure 1 shows a schematic of the studied model, which includes an isolated house with a height $(H)$ with two square openings $(0.2$ $H$ ) on the front wall of the house and two openings at the rear. The wall porosity (opening area divided by wall area) was 3\%. Two different configurations of inlet openings, Case-I and CaseII, were used in this study. The base of the house had dimensions $(3.33 \times 2.66) H$ and the length of the building was less than the maximum length $(5 H)$ suggested by Chu et al. [29] to obtain effective wind-driven cross ventilation. The building is partitioned inside as shown in Fig. 1; this layout is simple, and representative of an average family house in Iraq [32]. There are five rooms inside the building, including a kitchen (A), sitting room (B), living room (C), and two bedrooms (D and E). To simulate different window opening positions, two inlet-opening positions were used, as shown in Fig. 2a, with the front view of the building cases including dimensions shown in Fig. 2b. In both cases, the wind speed at the height of the building $\left(U_{r e f}\right)$ was $7 \mathrm{~m} / \mathrm{s}(R e=$ $13.9 \times 10^{3}$ ) with an angle of incidence of $0^{\circ}$.

\section{Numerical method}

CFD is based on the resolution of the governing equations that describe the flow-field in the computational domain. The governing equations describing air flow consist of continuity, momentum and turbulent modelling equations. The filtered continuity and momentum equations in LES are listed as follows [33]:

$$
\begin{gathered}
\frac{\partial \rho}{\partial t}+\frac{\partial\left(\rho \bar{u}_{i}\right)}{\partial x_{i}}=0 \\
\frac{\partial \overline{\rho u}_{i}}{\partial t}+\frac{\partial\left(\rho \bar{u}_{i} \bar{u}_{j}\right)}{\partial x_{j}}=-\frac{\partial \bar{p}}{\partial x_{i}}+\frac{\partial}{\partial x_{j}}\left\{\mu\left(\frac{\partial \bar{u}_{i}}{\partial x_{j}}+\frac{\partial \bar{u}_{j}}{\partial x_{i}}\right)\right\}-\frac{\partial \tau_{i j}}{\partial x_{j}}
\end{gathered}
$$


where $\bar{u}_{i}$ is the component of filtered instantaneous fluid velocity in the $x_{i}$ direction, $\bar{p}$ is the fluid pressure, $\rho$ is the fluid density, $\mu$ is the fluid dynamic viscosity, the bar '-' represents the spatial filtering and $\tau_{i j}$ represents the sub-grid scale tensor, the latter being modelled by the Smagorinsky model.

$$
\tau_{i j}=\left(\frac{1}{3}\right) \tau_{k k} \delta_{i j}-2 \mu_{t} \bar{S}_{i j}
$$

where $\sigma_{i j}$ is the subgrid-scale stress, $\bar{S}_{i j}$ is the rate of strain tensor of the resolved scale and $\mu_{t}$ is the viscosity of the sub-grid scale turbulence, which is defined as:

$$
\mu_{t}=\rho L_{s}^{2} \sqrt{2 \bar{S}_{i j} \bar{S}_{i j}}
$$

where $L_{s}$ is the mixing length for sub-grid scales and can be calculated as:

$$
L_{s}=\min \left(\kappa d, C_{s} V^{1 / 3}\right)
$$

where $\kappa$ is the Von Kármán constant, $d$ is the distance to the closest wall, $V$ is the volume of the computational cell and $C_{s}$ is the dynamic Smagorinsky coefficient, which is computed during the simulation using the information provided by the smaller scales of the resolved fields. The dynamic Smagorinsky coefficient approach has been employed in the field of computational wind engineering by various other researchers [34,35]. This coefficient varies with time and space, which allows the Smagorinsky model to cope with transitional flows and to include nearwall damping effects in a natural manner [36]. With this method, a second filter, referred to as the test filter (denoted with a curl), is applied to the once-filtered Navier-Stokes equations. The dynamic Smagorinsky coefficient can be calculated as:

$$
C_{s}=\frac{L_{i j} M_{i j}}{2 M_{i j} M_{i j}}
$$

where

$$
L_{i j}={\widetilde{u_{\imath}}}_{\bar{u}_{\jmath}}-\widetilde{\bar{u}}_{\imath} \widetilde{\bar{u}}_{J}
$$


and

$$
M_{i j}=\overline{|\bar{S}| \bar{S}_{l j}}-\tilde{\bar{\Delta}}^{2}|\tilde{\bar{S}}| \tilde{\bar{S}}_{i j}
$$

are the resolved stress and Germano rate of strain tensor, respectively [37].

\section{CFD model validation}

\subsection{Wind-tunnel experiment}

The CFD model is evaluated by measuring the flow over and through a cross-ventilation building model in a boundary layer wind tunnel (Ohba et al. [38]). The experiment was conducted in a wind tunnel of dimensions $1.2 \mathrm{~m}$ wide, $1.0 \mathrm{~m}$ high and $14.0 \mathrm{~m}$ long. As shown in Figure 3, the model was rectangular, measuring 1:2:2 with a height of $15 \mathrm{~cm}$ and a wall thickness of 0.75 $\mathrm{cm}$, and where the inlet and outlet openings have the same dimensions $(6 \mathrm{~cm}$ width and $3 \mathrm{~cm}$ height). The opening of the building model was placed perpendicular to the approaching flow and located at the centre of the windward and leeward sides of the building. The reference velocity was maintained at $7.0 \mathrm{~m} / \mathrm{s}$ at the upwind edge of the model; further details can be found in a previous study by the authors [32].

\subsection{CFD settings and parameters}

The computational model represents the reduced-scale model used in the experiments and follows the two best-practice guidelines in wind engineering described by Franke et al. [39] and Tominaga et al. [40]. The dimensions of the domain are $(22 \times 5 \times 12) H$. The computational grid is created using hexahedral cells inside the building and domain, and a grid independence study is conducted to ensure that the results are independent of the mesh resolution and yield a fully structured hexahedral grid with $4.1 \times 10^{6}$ cells. At the inlet of the domain, the vertical approachflow profiles of log-law mean wind speed, $U$, and turbulent kinetic energy, $k$, and specific dissipation rate, $\varepsilon$, are imposed, based on the measured incident profiles (Figure 4). The CFD 
code ANSYS Fluent 16.2 was used in the simulation, the Pressure Implicit with Splitting of Operator (PISO) algorithm was used for the pressure-velocity coupling, and the second-order discretisation scheme was used for the pressure interpolation. The bounded central-differencing scheme was used to discretise the convection term in the filtered momentum equation.

\subsection{CFD model validation results}

In order to validate the CFD model, the pressure coefficients at the middle of the inlet opening obtained from the numerical simulation were compared with the experimental data of Ohba et al. [38]. Figure 5 depicts a comparison between the predicted and measured pressure coefficients profiles.

As can be seen, the pressure coefficient above the windward opening showed good agreement with the experimental results, whilst for the leeward the pressure coefficient of the flow above the opening deviated notably from the experimental results. As regards the pressure coefficient under the opening, the CFD simulation predicted results that were very close to those derived from the experiment for both windward and leeward facades. Overall, the performance of the LES model is satisfactory, with Figure 5 showing good agreement between the two results. Further analysis regarding this comparison is provided in a previous study by the authors [32]. Although the geometry of the building that was used to validate the CFD model (Ohba et al. [38]) and that used in the current study (Figure 2) are not identical, there are sufficient points of similarity between them to consider the validation approach to be applicable for this type of building. For example, both buildings are isolated, and have a rectangular base. Both are exposed to a wind direction normal to the façade, the speed is fixed at $7 \mathrm{~m} / \mathrm{s}$ and the atmospheric boundary layer is considered to be the approach-flow. The roofs of both buildings are flat without any external features such as eaves, gutters and shingles. As a results, the notable features of the flow for the building studied by Ohba et al. [38] are also predicted for the building in the current study. 


\section{CFD cases study: settings and parameters}

In this section, the computational geometry, domain grid, boundary conditions and solver settings for the evaluation of the horizontal inlet opening position of an isolated family house are presented.

\subsection{Computational geometry, domain and grid}

A 3-D computational domain was constructed based on COST [39] and AIJ [40] guidelines, consisting of a rectangular house with height $H$ inside a duct $(23.3 \times 5 \times 12.6) H$, as shown in Fig. 6. The blockage ratio was $4.2 \%$, which is within the range recommended in the guidelines. A distance of $5 H$ was set between the inflow boundary and the building, whilst the outflow boundary was positioned $15 \mathrm{H}$ behind the building to allow the flow to redevelop in the wake region.

The numerical grid was generated by ICEM and hexahedral cells were used inside the house and domain. A fine mesh was constructed near the walls because the dynamic Smagorinsky model in the LES method requires a very high grid resolution in these regions, whilst a coarse mesh was used away from the walls and in all directions. The space between the walls of the house and the centre of the first cell was $0.005 \mathrm{H}$; the same distance was used for the ground, which is small enough to obtain $\mathrm{y}^{+}$around 1.4 and capture a laminar sub-layer. A grid expansion ratio of 1.15 or 1.2 was used between consecutive cells for the generation of the grid used in the simulation (Fig. 7).

Grid independence is an important factor in numerical simulations and is selected to find the effect of mesh size on results. The LES index of quality proposed by Celik et al. [41] is used to test the grid, and is dependent on the calculation of turbulent kinetic energy. The total kinetic 
energy, $k_{t}$, includes a resolved part, $k_{r e s}$, a subgrid scale part, $k_{s g s}$, and the numerical dissipation, $k_{\text {num }}$

$$
L E S \_I Q=\frac{k_{r e s}}{k_{t}}=\frac{k_{r e s}}{k_{r e s}+k_{S G S}+k_{\text {num }}}=1-\frac{k_{t}-k_{r e s}}{k_{t}}
$$

According to Pope [42], when $80 \%$ of the turbulent kinetic energy is resolved, a LES computation is considered to be well-resolved. The combined turbulent kinetic energy of numerical dissipation and the $S G S$ model based on Richardson extrapolation are assumed to scale with grid size/filter length [41]:

$$
k_{t}-k_{\text {res }}=a_{k} \Delta^{n}
$$

where $a_{k}$ is a coefficient that can be determined by running the LES on two grids with different resolutions, and where $n=2$ is the order of accuracy of the numerical scheme. The grid sensitivity analysis is performed for Case-I and two grids were chosen for this purpose: a coarse mesh (Grid A) with $3.5 \times 10^{6}$ cells, and a fine mesh (Grid B) with $6 \times 10^{6}$ cells. The profiles of $L E S \_I Q$ along lines $x / H=4.6,9$ and 12 are shown in Figure 8. The LES for the fine mesh (Grid B) resolved on average more than $80 \%$ of the turbulent kinetic energy, whilst the course mesh (Grid A) resolved less than that proposed by Pope [42]. Therefore, the fine mesh with $6 \times 10^{6}$ cells was chosen for the simulation of Case-I, whilst for Case-II the grid sensitivity analysis was not performed, as this latter case has almost the same number of grids $\left(6.1 \times 10^{6}\right.$ cells $)$ as Case-I.

\subsection{Boundary conditions and solver settings}

The inlet boundary conditions were based on the measurement incident profile of mean wind velocity. The inlet wind velocity profile is defined according to the logarithmic law. According to Richards and Hoxey [43], the vertical profiles of the mean wind velocity, turbulent kinetic energy and turbulent dissipation rate are imposed at the inlet of the domain. The equations used for the profiles are: 


$$
\begin{aligned}
& U(y)=\frac{u_{\tau}}{\kappa} \ln \left(\frac{y+y_{o}}{y_{o}}\right) \\
& k=\mathrm{a}\left(U I_{u}\right)^{2} \\
& \varepsilon=\frac{u_{\tau}{ }^{3}}{\kappa\left(y+y_{o}\right)}
\end{aligned}
$$

The inlet boundary conditions were used with equations (11)-(13) and the parameter, a, in eq. 12 is limited to 1.5 [32]. The value of $u_{\tau}$ is determined based on the values of the reference velocity $\left(U_{r e f}=7 \mathrm{~m} / \mathrm{s}\right)$ at a building height, $H$, and the aerodynamic roughness length, $y_{o}$. A timedependent inlet profile at the inlet of the domain was generated by the vortex method, where the number of vortices was $N=190$, this setting having been successfully tested in previous LES validation studies for wind flow around buildings[32, 34]. The lateral and the top sections of the domain were modelled as symmetry conditions, i.e., zero normal velocity and normal gradients for all variables. The surfaces of the house and the ground of the domain were modelled as noslip boundaries, whilst at the outlet of the domain the zero-gradient condition was used [44].

The CFD package, FLUENT R16.3, was used for numerical simulation prediction. The pressure-based solver was used in this study, where the flow was incompressible. The PISO algorithm was used for the pressure-velocity coupling and the second-order discretization scheme for the pressure interpolation. The bounded central-differencing scheme was used to discretize the convection term in the filtered momentum equation. Time discretisation was second-order implicit, and the convergence criterion was $10^{-5}$ for all terms. The time-step was set to $\Delta t=$ $0.0000075 \mathrm{~s}$ and kept constant during the simulation, which ensured that the Courant number was always smaller than 0.3 in most of the grid points with a maximal value of 0.6. The flow was initialized until the flow was fully developed and then, time-averaging and statistics collections are made for all the intended quantities were started. The initial transient conditions from the inlet of the duct and the total simulation time were continued until such a time as the flow became 
statistically steady. At this point, the total time for the simulation was found as 67,700 time-steps, which was equal to five time periods $\left(5 T^{*}\right)$, where dimensionless time, $T^{*}$, is defined as:

$$
T^{*}=t U_{\text {ref }} / L
$$

where $L$ is the length of the domain. The convergence of root-mean-square (RMS) quantities in unsteady flow was used for steady-state convergence. The transient run continued for a sufficiently long period of time (five times the flow-through time) until a statistically steady state was reached. To assess the quality of the LES analysis, a spectral analysis of certain quantities of interest were used. The way to achieve this is to extract a turbulent energy spectrum from the time history of the flow by performing a Fourier transform of the turbulent energy recorded over a long period of time. Examples of temporal evolution of the power density spectra $(P S D)$ at points near the building are shown in Fig. 9. The spectra in this figure show that the flow approaches fully turbulent and has a gradient of $-5 / 3$ in the roll-off.

\section{Impact of windward opening positions: CFD results}

The present study investigated the natural cross ventilation of a small-scale family house to ensure the physical comfort of the occupants. Two different inlet-opening configurations (CaseI, and II) were used to examine the impact of the windward inlet opening positions on the recirculation areas, flow pattern, and the ventilation rate inside a family house in order to determine which configuration is better. The inner layout of the building was kept the same for both configurations, and the schemes used for each case are shown in Figures 1 and 2. The flow enters from two openings in the front wall and exits from two openings in the rear wall of the house. The two inlet openings in Case-I are positioned near the centre of the building, whilst in Case-II the flow enters from openings near the sides of the building, whilst discharge is from openings located near the sides of the building for both cases. These four openings provide a high 
ventilation rate for the building. In order to investigate the impact of the positions of the inlet openings on cross ventilation, the area of the openings was kept constant in both cases, as was the wind speed at a constant of $7 \mathrm{~m} / \mathrm{s}$ at the height of the building, with wind direction normal to the openings.

\subsection{Mean flow and streamlines around the building}

The mean velocity and streamlines around the building in the vertical and horizontal planes for both cases are presented in Figs. 10 and 11, respectively. The major feature shown outside the building is the formation of three main recirculation zones at the two side walls and the roof of the building because of the low-pressure zones produduced in these regions, as shown in Figure 12. In addition, the low-pressure zone behind the building also produced a large circulation zone in both cases. The two kidney vortices covered one-third of the length of the right and the left side of the building, and seemed to be equal in their dimensions due to the almost-symmetrical flow. The third kidney vortex covered one-third of the length of the roof of the building near the edge of the roof itself. The upstream airflow is accelerated because it hits the edges of the roof and laterals of the building, reaching a maximum velocity of $9.2 \mathrm{~m} / \mathrm{s}$. Generally, these figures showed the same patterns of flow around the building in both cases, where the size of all vortices was found to be approximately the same. These results show that the position of the inlet openings has no significant effect on the flow behaviour around the building for these configurations, and most of the impact will probably occur inside the building.

\subsection{Mean flow pattern inside the building}

Air velocity countours of a horizontal plane at $1.7 \mathrm{~m}$ are presented in Fig. 13. The main feature of the indoor flow for both cases is the momentum of the incoming airflow, which is hindered by the interior walls of rooms A and B in the streamwise direction, thus causing the airflow paths to change direction. The airflow swerves to the $z$-and $x$-directions, the flow in the 
$x$-direction moves directly to the leewards rooms and represents the main cause of high indoor turbulent kinetic energy, whilst the air flow in the $z$-direction rotates inside rooms A and B, creating a circulation zone inside these two rooms. The airflow in Case-II swerves towards the $z$-direction and then moves to the other rooms; whilst the flow path in the lateral direction in Case-I is lower, the inflow stream coming from rooms A and B is restricted to flowing leeward (rooms D and E) and can thus supply high ventilation to the leeward rooms. Air velocity is an important factor in determining the levels of indoor thermal comfort [45], and the velocities of the zones near the inner walls in rooms A and B for both cases are higher than the maximum acceptable velocity $(0.8 \mathrm{~m} / \mathrm{s})$ recommended by ASHRAE guidelines. Therefore, it will be difficult for the designer to create acceptable indoor thermal comfort for the occupants of these rooms. In room C, the airflow velocity is low for both cases, with the area of high velocity (green area $>0.3$ ) in Case-I being higher than for Case-II; a still-air zone is produced in the middle of the room, and a high concentration of $\mathrm{CO}_{2}$ may result from the presence of people. Regarding rooms $\mathrm{D}$ and $\mathrm{E}$, the two cases show the same patterns, with half of the rooms showing very low air velocities because of weak circulation in these zones. These zones will become stagnation zones with low ventilation rates resulting in less mixing of air, and therefore inner re-topology is necessary for rooms $\mathrm{D}$ and $\mathrm{E}$.

\subsection{Streamlines inside the building}

Figures 14 presents the mean average velocity streamlines of the airflow at the plane crossing the middle of the inlet openings. In addition, the mean average velocity streamlines in the vertical section $(x y)$ in the middle of rooms A and room B are presented in Fig. 15. For both cases, the first figure shows that a recirculation zone forms, especially in rooms A and B, in which the flow enters the house directly through the two openings, whilst the recirculation is weaker in rooms D and $\mathrm{E}$. The strong circulation inside rooms A and B is due to the low-pressure regions at their 
centres and high-pressure regions near the interior walls, as shown in Fig. 15. Regarding CaseI, the streamlines of the flow are normal to the openings, producing two circulation zones in opposite directions (clockwise in room B and anticlockwise in room A), whereas in Case-II the flow enters near the lateral walls at an angle of approximately $45^{\circ}$ to the inner walls, producing large circulation zones inside the two rooms that flow in opposite directions to those in Case-I due to the flow hitting the windward wall and separating on both sides of the building as a result of low-pressure zones at the lateral sides of the building (Figs. 11 and 12). As the positions of the inlet openings are located near the centre of the building in Case-I, this configuration can supply more air to the other rooms, which would be of interest to architects who want high aeration inside buildings. The results of both cases show that the recirculation zone in room A is more intense than in room B due to the fact that room B is smaller than room A. Furthermore, the gradient of the pressure coefficients for room A is larger than that for room B, especially in Case-II, which increases the rotation of the flow as shown in Fig. 16. The vertical section through the streamlines shows that the recirculation zones in each case are different, especially in rooms A and B. Regarding Case-I, two large circulation zones are formed that divide the room into two zones, whilst a large circulation zone is formed in Case-II, mixing air from the bottom to the top. The circulation inside room $\mathrm{C}$ is the same in both cases, but in Case-I is more intense at the centre, which may cause a high concentration of $\mathrm{CO}_{2}$ at the middle of the room. Regarding room $\mathrm{D}$, a circulation zone, which is produced at high level in Case-II, is larger and more intensive than Case-I, whereas in room E (Case-I) a full circulation zone is produced and covers the room. In general, most of the rooms in Case-II show airflow mixing that is better than Case-I, and it could therefore be easier for a designer to obtain proper thermal comfort inside the rooms in Case-I.

\subsection{Instantaneous wind flow patterns}


Instantaneous wind flow patterns can be obtained from the LES, and Figs. 17 and 18 show the flow pattern at different flow times for both cases. They dominate the flow structure in and around the building at different instants in time for Case-I $\left(2.6 T^{*}, 3.5 T^{*}, 4.1 T^{*}\right)$, and Case-II $\left(2.5 T^{*}, 3.6 T^{*}\right.$, $\left.4.5 T^{*}\right)$. It can been seen that the flow patterns are irregular and complicated in the horizontal plane. The flow changes its direction with time and this has a significant impact on the flow pattern inside the building, subsequently affecting the strength of circulation areas inside rooms.

\subsection{Fluctuating ventilation rate}

Generally, the ventilation flow rate always fluctuates through openings, especially for windinduced ventilation; thus, the description of ventilation flow rate may be insufficient if the scale of the fluctuations in the flow rate are large [24]. As shown in Fig. 19, large fluctuations can be found near the leeward side, and the top and lateral walls of the building due to high-frequency flow and separating flow at the leading edges. The transient evolution of the ventilation rates through the two inlet openings is provided in Fig. 20 for both cases, where the dimensionless ventilation rate, $Q^{*}$, based on the reference velocity, is defined as:

$$
\mathrm{Q}^{*}=\mathrm{Q} / \mathrm{U}_{\mathrm{ref}} \mathrm{A}
$$

in which $A$ is the opening area. Comparison of openings aerating flow can be very important when one wishes to design houses with high ventilation efficiencies. The standard deviation denotes the fluctuating turbulence intensity of the instantaneous ventilation. Figure 20 shows that the maximum standard deviation is 0.16 at opening-2 (Case-II) whilst the minimum is 0.11 at the same opening for Case-I. Although large fluctuations can be found in both cases, the influence of small-scale fluctuations is greater due to the low frequency of the flow. In addition, the turbulence intensity (ratio of the RMS of the velocity fluctuations in the $x$-direction, $\mathrm{u}_{\mathrm{rms}}$, to the local mean flow velocity, $\mathrm{u}_{\text {mean, }}$ in the $x$-direction) at both openings was higher for Case-II than for Case-I, as shown in Fig. 21, which indicates that the flow is more turbulent near the openings 
in Case-II than Case-I. Straw [12] mentions that the standard deviation of ventilation rates can be considered to be induced by turbulence since the fluctuation of a wind-induced ventilation rate is caused by the turbulence impact of wind. Consequently, the ratio of the standard deviation to the dimensionless ventilation rate indicates the magnitude of the turbulence-induced component in the total ventilation rate.

The ratios of the standard deviation to the dimensionless ventilation rates of openings 1 and 2 for Case-I are about $23 \%$ and $21 \%$, respectively, which indicates the extent of the role of the turbulence-induced ventilation rate in the total ventilation rate, whilst for Case-II this ratio is higher, and represents about $33 \%$ for both openings. Accordingly, as the mean stream of the flow provides at least $67 \%$ of the total ventilation rate in Case-II and more than $78 \%$ in Case-I, it can be concluded that the main source of momentum for air exchange is provided by the mean flow. As a result, the largest ventilation rate occurs in Case-I because the ratio of mean flow to turbulent flow in this case is larger than for Case- II, as shown in Fig. 22. In additon, In comparision with Case-II, Case-I has less resistance to the incoming air flow, where the two windward inlet openings are aligned with the corridors that go into rooms D and E, which is another reason why Case-I reaches the highest volume flow rate. In general, the results showed that the rate of ventilation of Case-I is higher than for Case-II by $10 \%$, and this configuration would interest any designer seeking a higher ventilation rate. Comparison of aerating flow openings can be very important for designers who want to design houses with high ventilation efficiencies.

\subsection{Turbulent kinetic energy}

Fig. 23 compares the distribution of the turbulent kinetic energy fields in the horizontal section perpendicular to the openings for the two cases. In front of the building, the turbulent kinetic energy in Case-II is higher than for Case-I, and therefore, the flow at the openings is more turbulent in Case-II than in Case-I. Furthermore, the turbulent intensity profile shows the same 
trend, which explains the larger spread of the mixing layer observed in Case-II than in Case-I (Fig. 21).

Regarding the indoor turbulent kinetic energy, the figure shows that the turbulent kinetic energy in Case-I is higher than in Case-II. Therefore it seems that the indoor turbulent kinetic energy depends on the rate of ventilation because the indoor turbulent kinetic energy represents the airflow power of the entire building space transported from the ambient wind through the openings and thus accounts for the characteristics of the indoor airflow, such as with a low speed and high turbulence intensity [46].

This relationship implies the conclusion that openings near the sides windward of the building result in less fluctuation of indoor turbulent kinetic energy than openings located in the middle. As the wind comfort inside the building can be more easily achieved when the air has lower indoor kinetic energy [32], so the first configuration (Case-I) would not be chosen by a designer who wanted comfortable rooms because of the high amount of air movement inside the rooms. In contrast, Case-I could be better for hot and/or humid weather conditions where higher air velocities are needed to obtain thermal comfort.

\section{Discussion}

\subsection{Comparison with previous work}

A comparison between the two geometries of the current study and previous studies from the literature is difficult due to various differences in geometry, which are complicated even further due to the different geometries used, different velocity profiles and turbulence levels being compared, etc. In addition, the partitions inside the geometry (multi-zones) make the comparison even more difficult when comparing the current geometry with a one-zone geometry or with a building with different internal partitioning. Despite these differences, there are some points that 
can be contrasted and discussed. First, the current study agrees with those of Karava et al. [11] and Tominaga et al. [9] regarding the nature of the recirculation region in terms of vortex centre, size, and sense of rotation being mainly governed by inlet opening position. Second, the current study focuses on horizontal opening positions concluding that an opening near the centre of the windward face can provide for a greater ventilation rate for the building with openings located at lateral positions. It should be pointed out that the two references mentioned above focused on the vertical location of openings and concluded that the opening located at the centre of the front façade of the building provides a lower flow rate than an opening located at a higher level.

\subsection{Limitations and further research}

The main goal of this study on wind-driven cross-ventilation is to evaluate the impact of windward horizontal-opening positions on the fluctuation in ventilation rate and flow fields in a family house for a normal wind incidence angle $\left(\theta=0^{\circ}\right)$. Two different configurations of inlet openings (Case-I and Case-II) are used in the analyses. It is important to note a number of limitations in this work, which should be considered in any future research:

- $\quad$ An isolated buildings was used in this study, so future work should focus on buildings surrounded by other buildings, external fences and areas of greenery. Inside the building, only one configuration was used for the two cases, and the building was empty without furniture, doors and occupants.

- $\quad$ The study neglected the magnitude of the wind speed, which plays an important role on the air change rate of a building, and further the wind direction was normal to the front $\left(\theta=0^{\circ}\right)$ of the building, so different wind angles should be used in further research, especially $\theta=30^{\circ}, 90^{\circ}$ and $45^{\circ}$.

- A simplistic outer form of the building was used whilst other configurations, such as shape and height of the roof, length and shape of the eaves, or overhang, were ignored. 
- The simulations in this study were performed for an isothermal situation, whilst future work should focus on non-isothermal situations to study the effect of temperature gradients inside the building and on human thermal comfort.

\section{Conclusion}

Natural cross ventilation in a small-scale building exposed to outdoor conditions was investigated numerically using CFD analysis. A widely-used turbulence model in the ventilation section, the Smagorinsky LES model, was performed for this geometry, and the results validated against available experimental data from the literature. In this study, openings were shown to be an important design factor in terms of its effect on the air-stream pattern inside a building. The numerical approach used in such studies gives the architect the best view of the natural mechanisms of ventilation in a building by providing further insight into the induced flow-field inside and around it, with information that would not otherwise be produced by experimental methods. Despite certain limitations to this study, such as the impacts of direction and speed of the wind, shape of the openings, surrounding buildings, etc., the following conclusions were obtained:

- The rate of contributing turbulent flow in total ventilation rate depends on the position of the inlet openings. In Case-II, where the openings were near the side wall, this contribution was $33 \%$, whilst in Case-I, the turbulent flow contributed on average only $22 \%$ to the total ventilation rate.

- In consistent with previous studies [11], the indoor air flow pattern changes when the positions of the inlet openings are changed, which also changes the direction of circulation inside a room from clockwise to anticlockwise or from horizontal to vertical circulation. 
- The flow rates of openings located near the centre of the building were steadier than the flow rates of openings located near the sides of the building.

- The ventilation rate depends on the positions of the windward inlet openings; the geometry of Case-I provides better results that of Case-II by $10 \%$.

- Based on the results, strong recirculation formed in rooms A and B with weaker recirculation formed in rooms $\mathrm{D}$ and $\mathrm{E}$; this is better for a designer who desires weaker recirculation in a building.

\section{Acknowledgements}

The financial support from the Ministry of Higher Education and Scientific Research of Iraq is gratefully appreciated.

\section{References}

[1] Ahmed AQ, Gao S, Kareem AK. A numerical study on the effects of exhaust locations on energy consumption and thermal environment in an office room served by displacement ventilation. Energy Conversion and Management. 2016;117:74-85.

[2] Larsen TS, Heiselberg P. Single-sided natural ventilation driven by wind pressure and temperature difference. Energy and Buildings. 2008;40:1031-40.

[3] Larsen TS. Natural ventilation driven by wind and temperature difference: Aalborg Universitet, Denmark.; 2006.

[4] Kato S, Murakami S, Mochida A, Akabayashi S-i, Tominaga Y. Velocity-pressure field of cross ventilation with open windows analyzed by wind tunnel and numerical simulation. Journal of Wind Engineering and Industrial Aerodynamics. 1992;44:2575-86.

[5] Ernest D, Bauman F, Arens E. The effects of external wind pressure distributions on windinduced air motion inside buildings. Journal of Wind Engineering and Industrial Aerodynamics. 1992;44:2539-50.

[6] Kindangen J, Krauss G, Depecker P. Effects of roof shapes on wind-induced air motion inside buildings. Building and Environment. 1997;32:1-11.

[7] Elmualim AA, Awbi HB. Wind tunnel and CFD investigation of the performance of "Windcatcher" ventilation systems. International Journal of ventilation. 2002;1:53-64.

[8] Evola G, Popov V. Computational analysis of wind driven natural ventilation in buildings. Energy and buildings. 2006;38:491-501.

[9] Tominaga Y, Blocken B. Wind tunnel analysis of flow and dispersion in cross-ventilated isolated buildings: impact of opening positions. Journal of Wind Engineering and Industrial Aerodynamics. 2016;155:74-88. 
[10] Ohba M, Goto T, Kurabuchi T, Endo T, Akamine Y. Experimental study on predicting winddriven cross-ventilation flow rates and discharge coefficients based on the local dynamic similarity model. International Journal of Ventilation. 2006;5:105-14.

[11] Karava P, Stathopoulos T, Athienitis A. Airflow assessment in cross-ventilated buildings with operable façade elements. Building and Environment. 2011;46:266-79.

[12] Straw M, Baker C, Robertson A. Experimental measurements and computations of the windinduced ventilation of a cubic structure. Journal of Wind Engineering and Industrial Aerodynamics. 2000;88:213-30.

[13] Yang T. CFD and field testing of a naturally ventilated full-scale building: University of Nottingham, The United Kingdom; 2004.

[14] Stavrakakis G, Koukou M, Vrachopoulos MG, Markatos N. Natural cross-ventilation in buildings: Building-scale experiments, numerical simulation and thermal comfort evaluation. Energy and Buildings. 2008;40:1666-81.

[15] Ramponi R, Blocken B. CFD simulation of cross-ventilation flow for different isolated building configurations: validation with wind tunnel measurements and analysis of physical and numerical diffusion effects. Journal of Wind Engineering and Industrial Aerodynamics. 2012;104:408-18.

[16] Perén J, van Hooff T, Leite B, Blocken B. Impact of eaves on cross-ventilation of a generic isolated leeward sawtooth roof building: Windward eaves, leeward eaves and eaves inclination. Building and Environment. 2015;92:578-90.

[17] Perén JI, van Hooff T, Leite B, Blocken B. CFD simulation of wind-driven upward cross ventilation and its enhancement in long buildings: Impact of single-span versus double-span leeward sawtooth roof and opening ratio. Building and Environment. 2016;96:142-56.

[18] Perén J, Van Hooff T, Leite B, Blocken B. CFD analysis of cross-ventilation of a generic isolated building with asymmetric opening positions: impact of roof angle and opening location. Building and Environment. 2015;85:263-76.

[19] Derakhshan S, Shaker A. Numerical study of the cross-ventilation of an isolated building with different opening aspect ratios and locations for various wind directions. International Journal of Ventilation. 2017;16:42-60.

[20] Kurabuchi T, Ohba M, Endo T, Akamine Y, Nakayama F. Local dynamic similarity model of cross-ventilation part 1-theoretical framework. International Journal of Ventilation. 2004;2:371-82.

[21] Ohba M, Kurabuchi T, Tomoyuki E, Akamine Y, Kamata M, Kurahashi A. Local Dynamic Similarity Model of Cross-Ventilation Part 2-Application of Local Dynamic Similarity Model. International Journal of Ventilation. 2004;2:383-94.

[22] Hawendi S, Gao S. Investigation of Opening Positions on the Natural Ventilation in a LowRise Building by CFD Analysis. Proceedings of the 3rd International Conference on Fluid Flow, Heat and Mass Transfer (FFHMT'16, Paper No151). Ottawa, Canada 2016.

[23] Jiang Y, Chen Q. Study of natural ventilation in buildings by large eddy simulation. Journal of Wind engineering and industrial aerodynamics. 2001;89:1155-78.

[24] Jiang Y, Chen Q. Effect of fluctuating wind direction on cross natural ventilation in buildings from large eddy simulation. Building and Environment. 2002;37:379-86.

[25] Jiang Y, Alexander D, Jenkins H, Arthur R, Chen Q. Natural ventilation in buildings: measurement in a wind tunnel and numerical simulation with large-eddy simulation. Journal of Wind Engineering and Industrial Aerodynamics. 2003;91:331-53.

[26] Hu C-H, Ohba M, Yoshie R. CFD modelling of unsteady cross ventilation flows using LES. Journal of Wind Engineering and Industrial Aerodynamics. 2008;96:1692-706. 
[27] Lund TS, Wu X, Squires KD. Generation of turbulent inflow data for spatially-developing boundary layer simulations. Journal of Computational Physics. 1998;140:233-58.

[28] Chu C-R, Chiang B-F. Wind-driven cross ventilation with internal obstacles. Energy and Buildings. 2013;67:201-9.

[29] Chu C-R, Chiang B-F. Wind-driven cross ventilation in long buildings. Building and Environment. 2014;80:150-8.

[30] Tuan L, Razak AA, Zaki S, Mohammad A, Hassan M. Large eddy simulation of natural ventilation for idealized terrace houses due to the effect of setback distance. IOP Conference Series: Materials Science and Engineering. Selangor, Malaysia: IOP Publishing; 2015. p. 012009.

[31] van Hooff T, Blocken B, Tominaga Y. On the accuracy of CFD simulations of crossventilation flows for a generic isolated building: comparison of RANS, LES and experiments. Building and Environment. 2017;114:148-65.

[32] Hawendi S, Gao S. Impact of an external boundary wall on indoor flow field and natural cross-ventilation in an isolated family house using numerical simulations. Journal of Building Engineering. 2017;10:109-23.

[33] FLUENT User's Guide, November 2013.

[34] Gousseau P, Blocken B, Stathopoulos T, Van Heijst G. CFD simulation of near-field pollutant dispersion on a high-resolution grid: a case study by LES and RANS for a building group in downtown Montreal. Atmospheric Environment. 2011;45:428-38.

[35] Porté-Agel F, Pahlow M, Meneveau C, Parlange MB. Atmospheric stability effect on subgrid-scale physics for large-eddy simulation. Advances in Water Resources. 2001;24:1085102.

[36] Germano M, Piomelli U, Moin P, Cabot WH. A dynamic subgrid-scale eddy viscosity model. Physics of Fluids A: Fluid Dynamics. 1991;3:1760-5.

[37] Kim W-W, Menon S, Kim W-W, Menon S. Application of the localized dynamic subgridscale model to turbulent wall-bounded flows. 35th aerospace sciences meeting and exhibit. American Institute of Aeronautics and Astronautics, Reno, USA.1997. p. 210.

[38] Ohba M, Irie K, Kurabuchi T. Study on airflow characteristics inside and outside a crossventilation model, and ventilation flow rates using wind tunnel experiments. Journal of Wind Engineering and Industrial Aerodynamics. 2001;89:1513-24.

[39] Franke J, Hellsten A, Schlunzen KH, Carissimo B. The COST 732 Best Practice Guideline for CFD simulation of flows in the urban environment: a summary. International Journal of Environment and Pollution. 2011;44:419-27.

[40] Tominaga Y, Mochida A, Yoshie R, Kataoka H, Nozu T, Yoshikawa M et al. AIJ guidelines for practical applications of CFD to pedestrian wind environment around buildings. Journal of wind engineering and industrial aerodynamics. 2008;96:1749-61.

[41] Celik I, Cehreli Z, Yavuz I. Index of resolution quality for large eddy simulations. Journal of fluids engineering. 2005;127:949-58.

[42] Cant S. SB Pope, Turbulent Flows, Cambridge University Press, Cambridge, UK, 2000, 771 pp. Elsevier; 2001.

[43] Richards P, Hoxey R. Appropriate boundary conditions for computational wind engineering models using the $\mathrm{k}-\epsilon$ turbulence model. Journal of wind engineering and industrial aerodynamics. 1993;46:145-53.

[44] Jiang Y, Su M, Chen Q. Using large eddy simulation to study airflows in and around buildings. ASHRAE Transactions. 2003;109:517-26. 
[45] Park D. The Application of the Solar Chimney for Ventilating Buildings: Virginia Tech, Blacksburg, USA; 2016.

[46] $\mathrm{Bu} \mathrm{Z}$, Kato S. Wind-induced ventilation performances and airflow characteristics in an areaway-attached basement with a single-sided opening. Building and Environment. 2011;46:911-21.

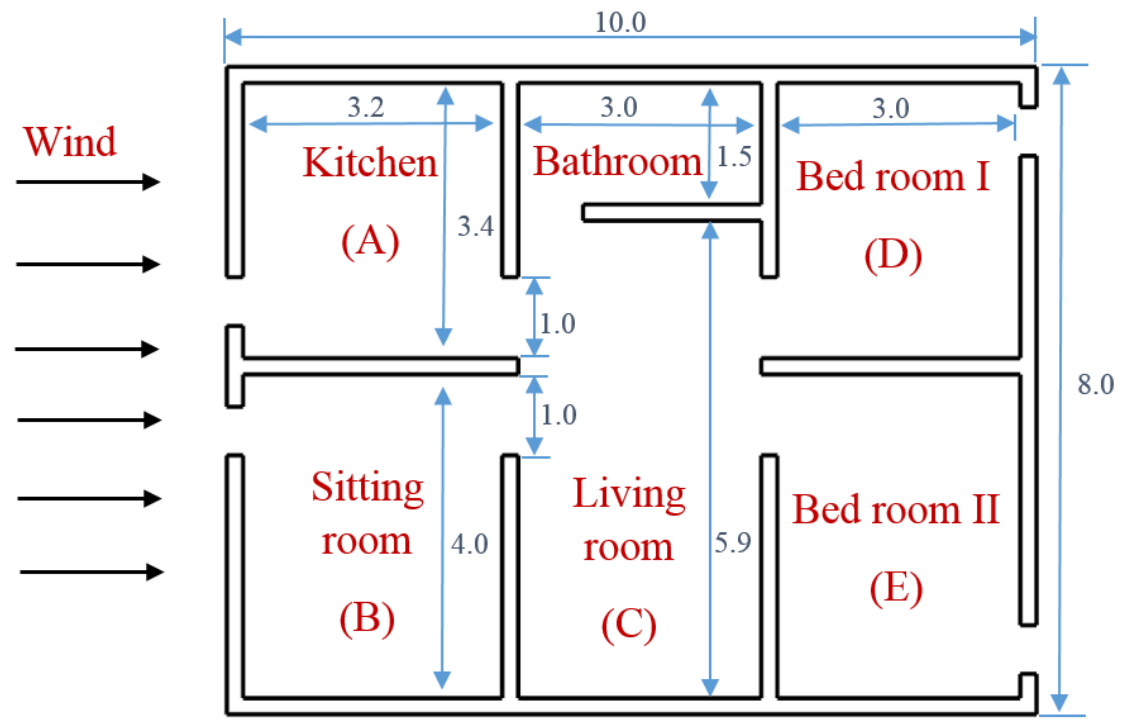

Fig. 1 
a)
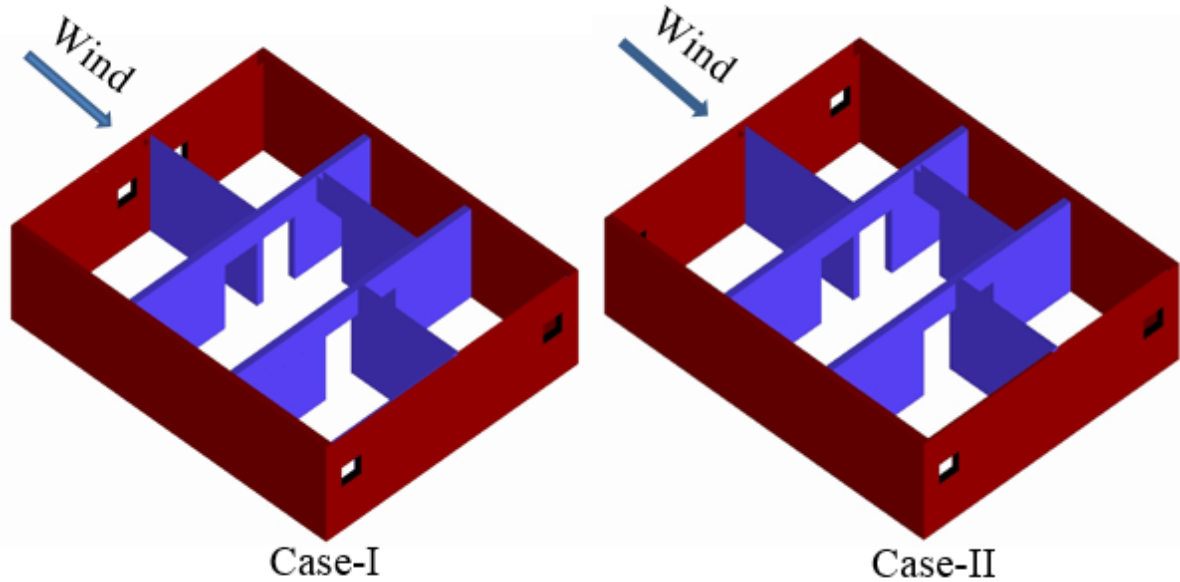

b)
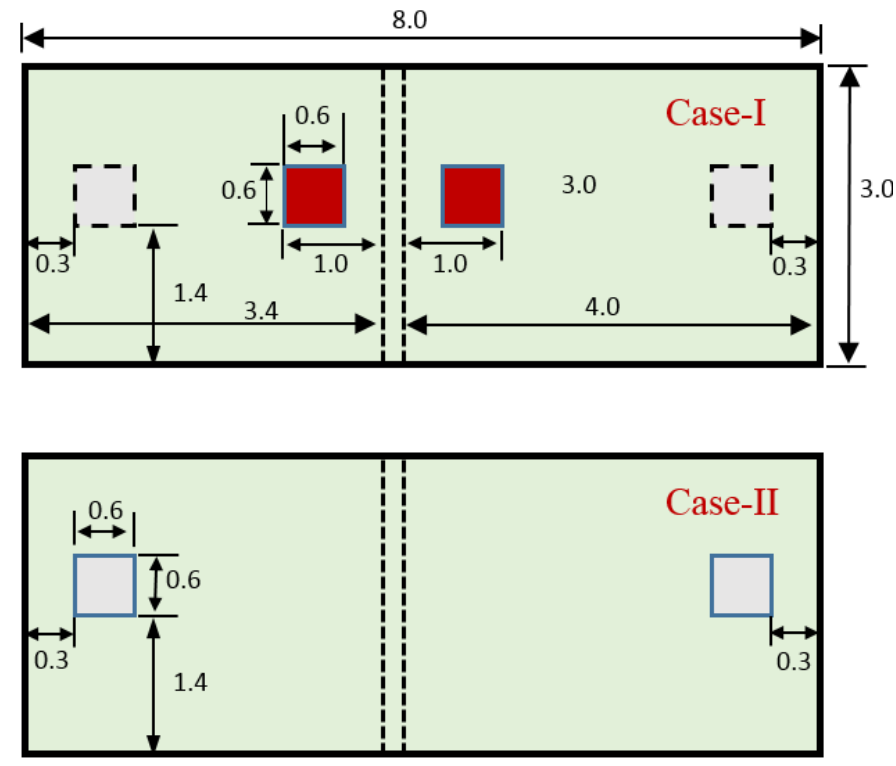

Fig. 2 
a)

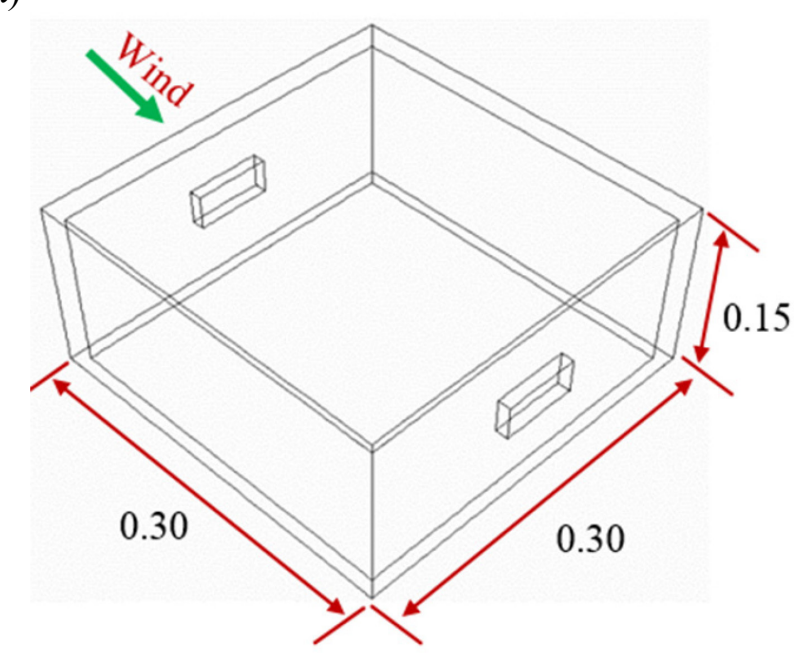

b)

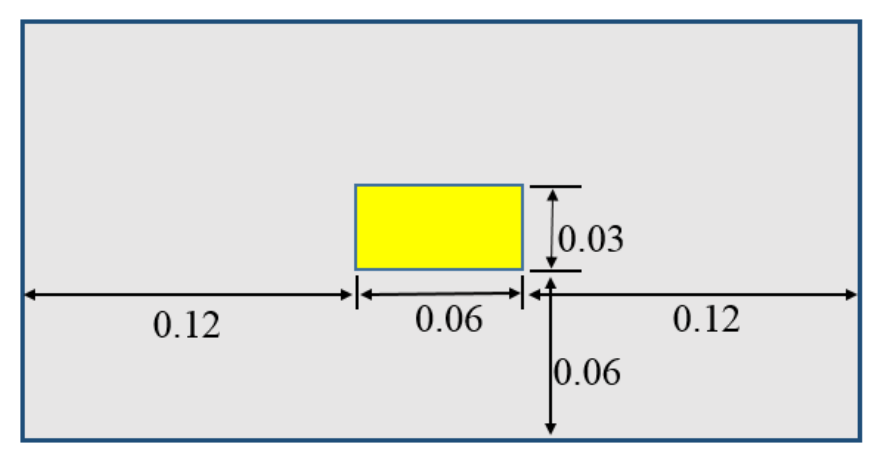

Fig. 3

a)

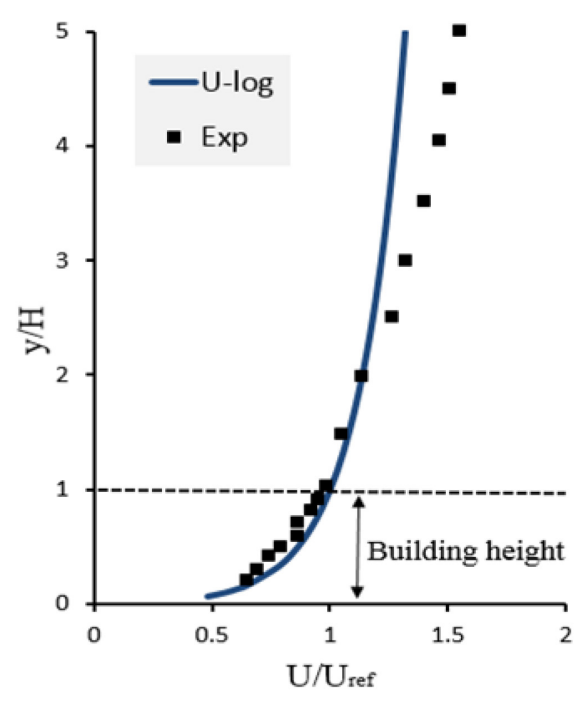

b)

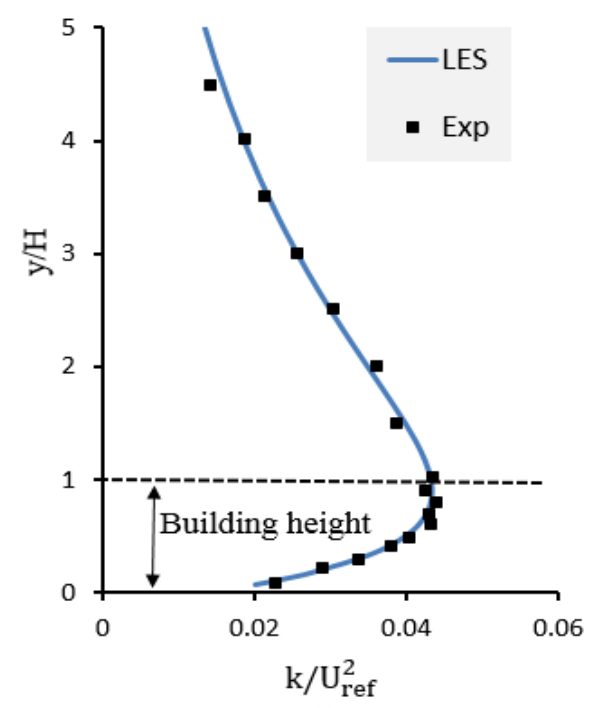

Fig.4 


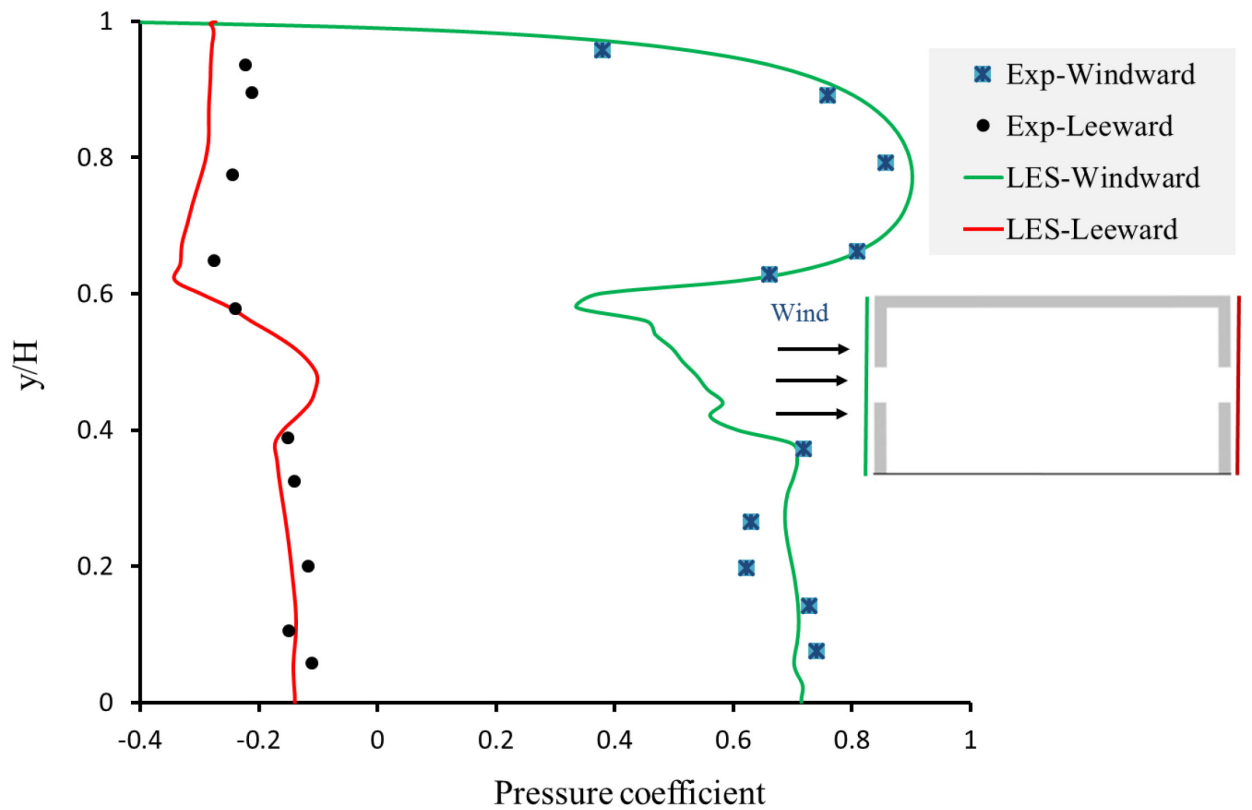

Fig. 5

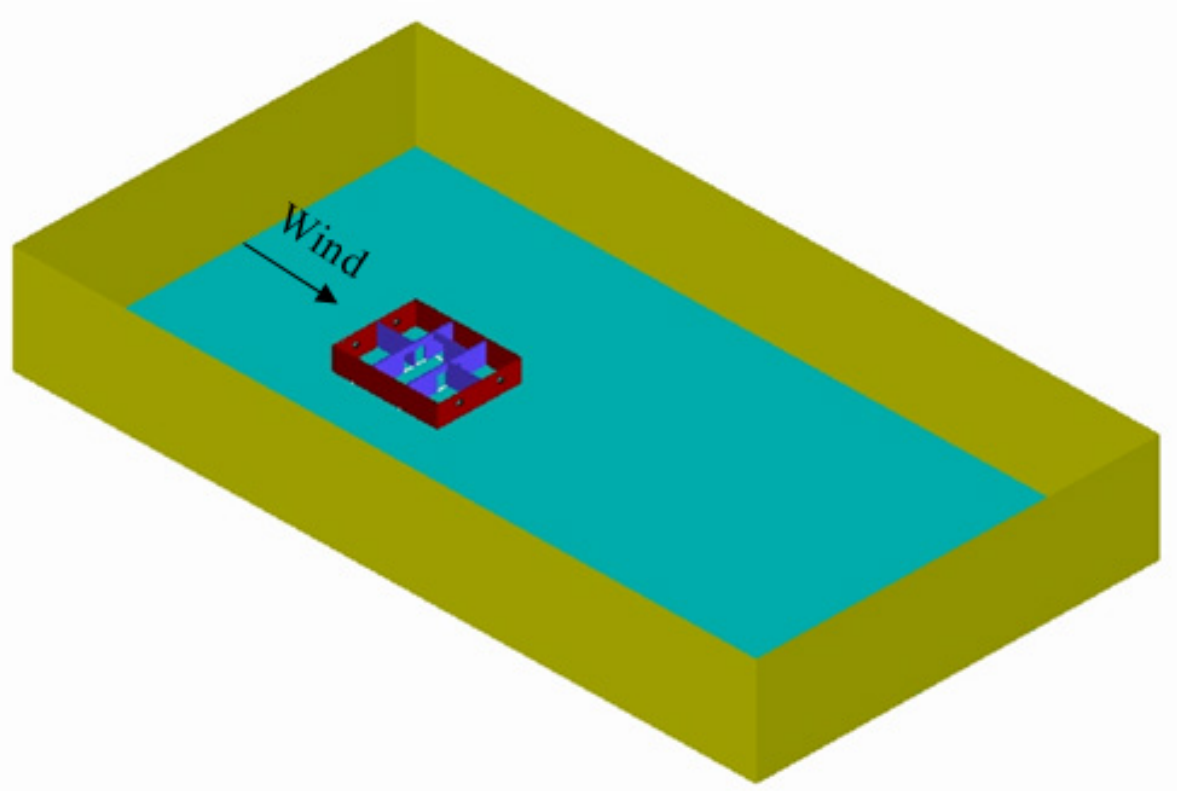

Fig. 6 


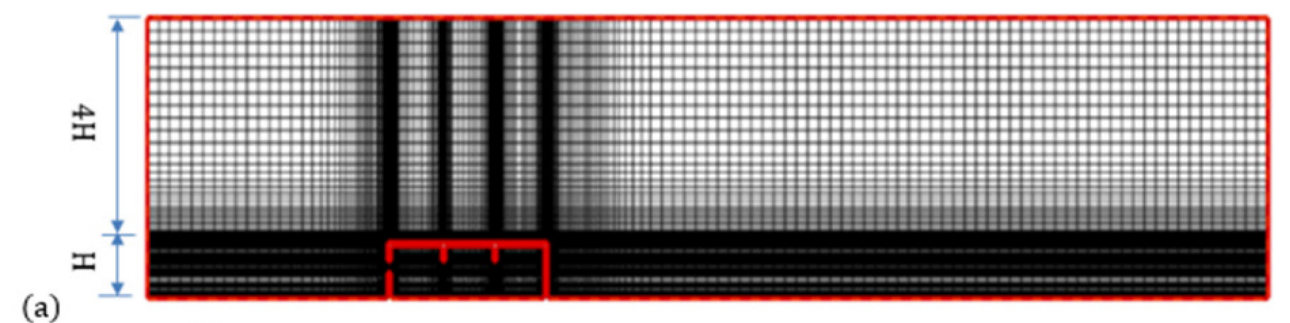

(a)

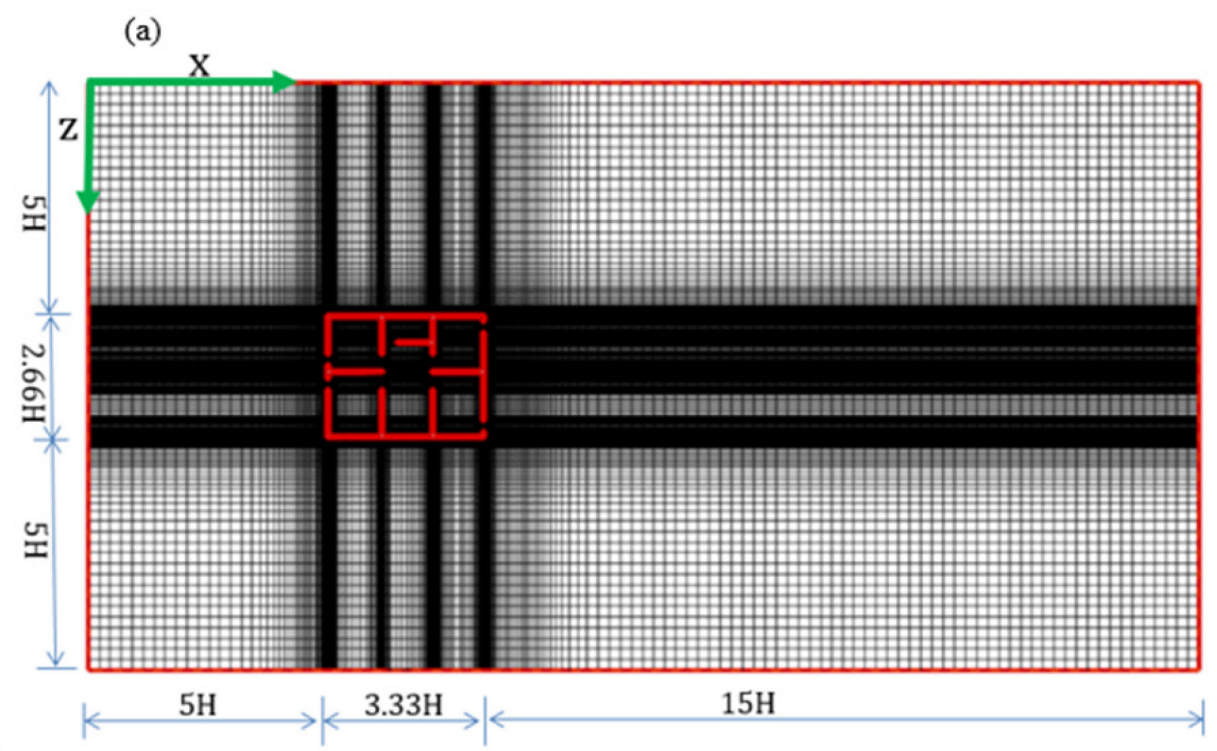

(b)

Fig. 7

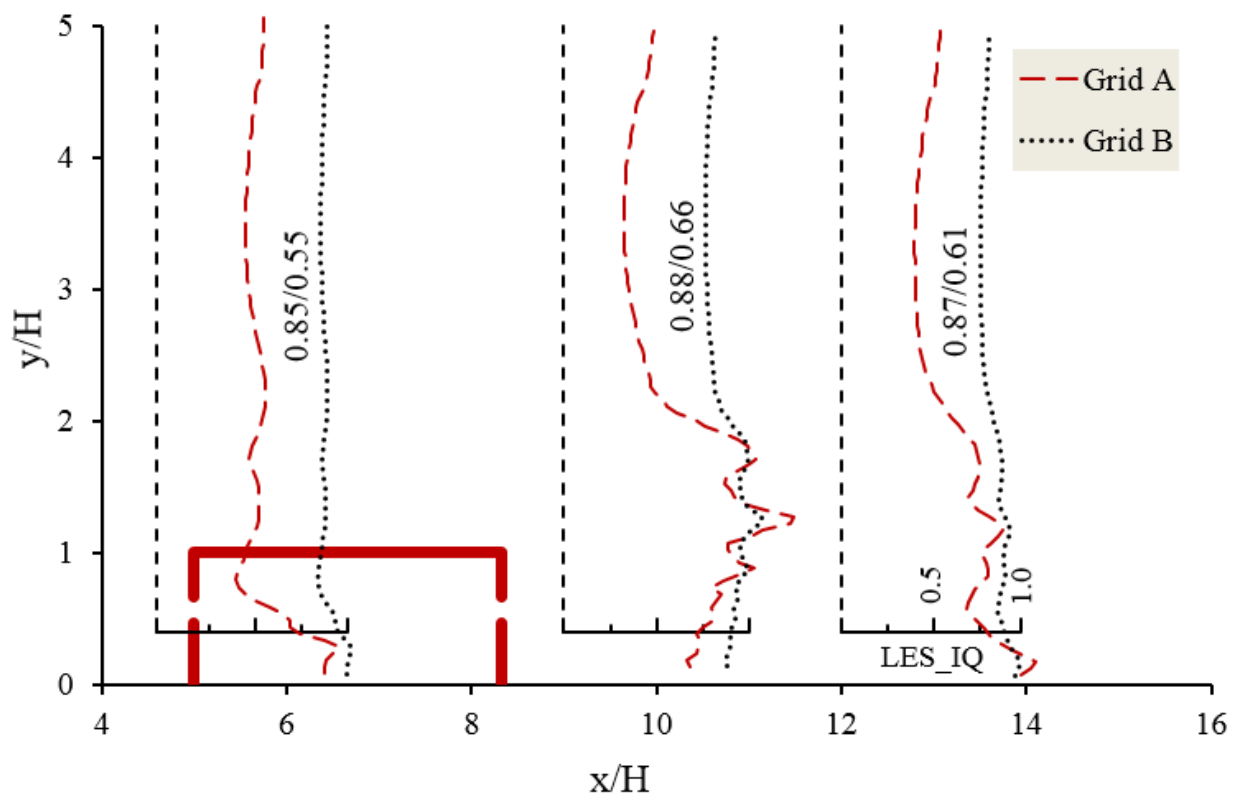

Fig. 8 

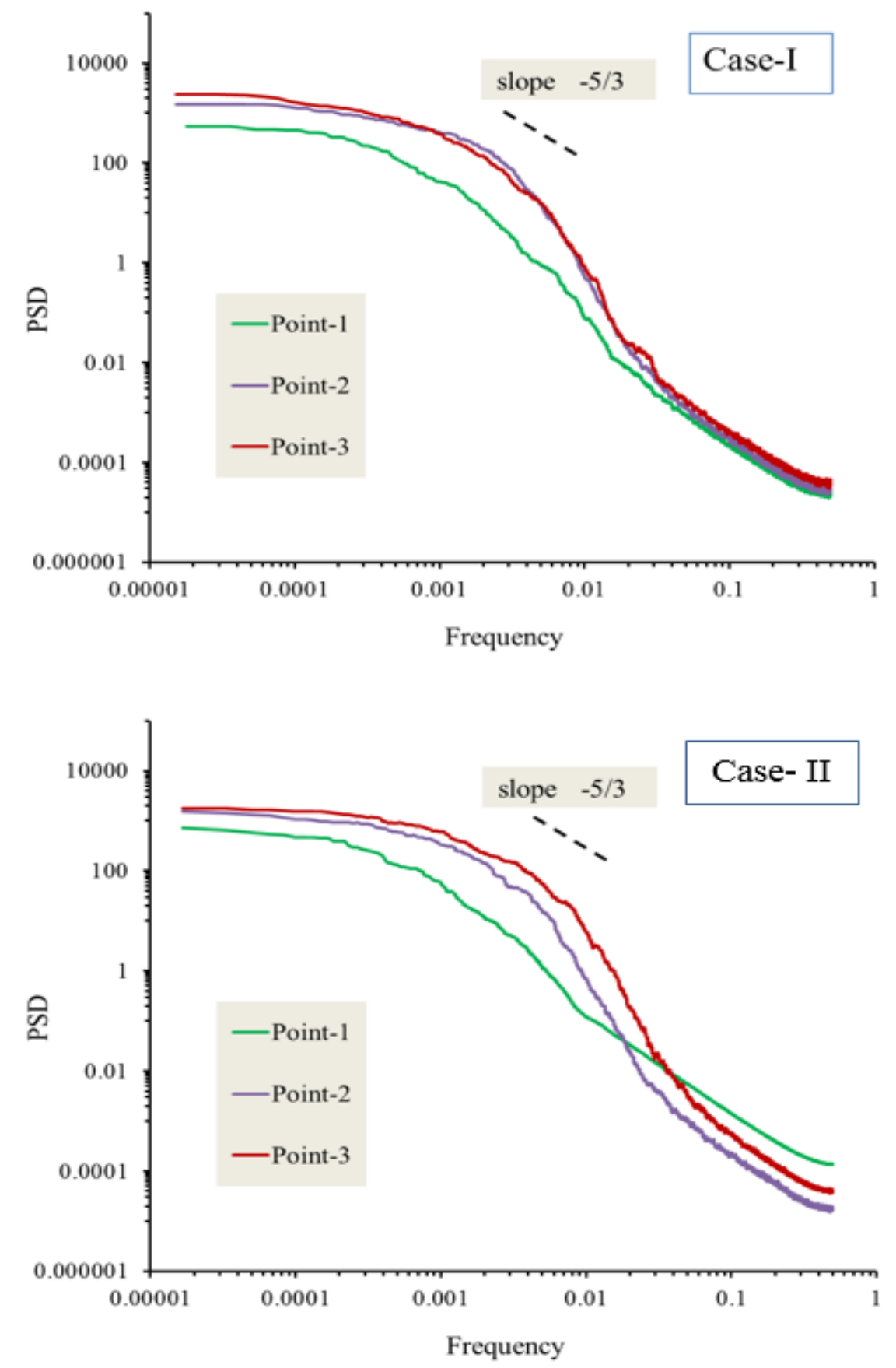

Fig. 9 

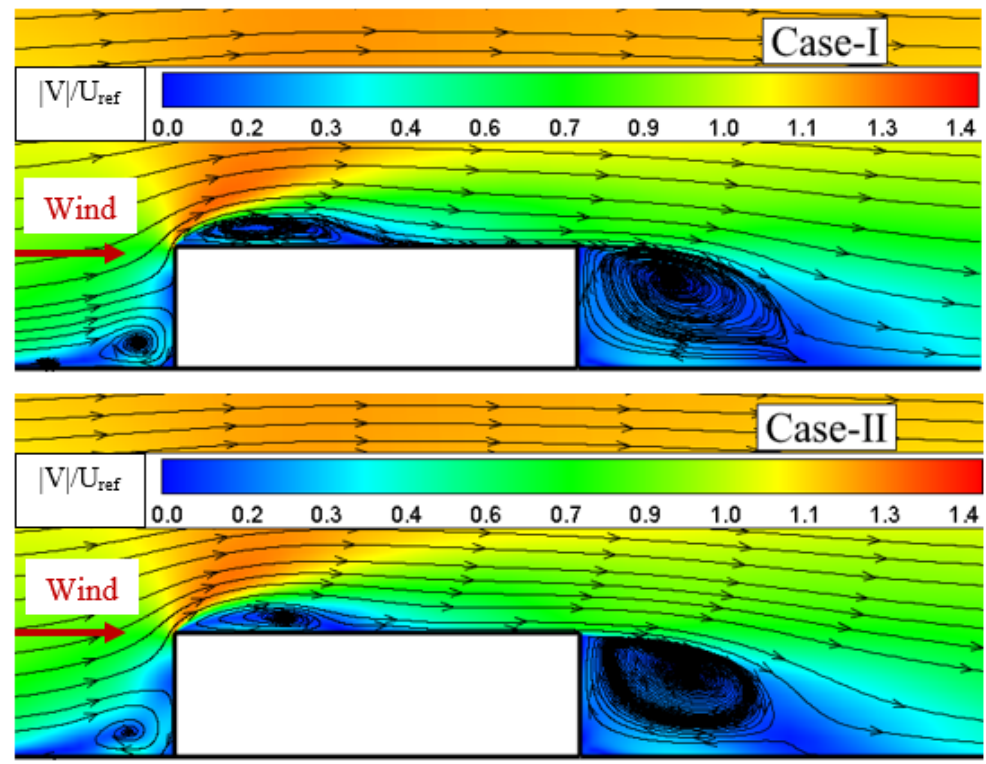

Fig. 10
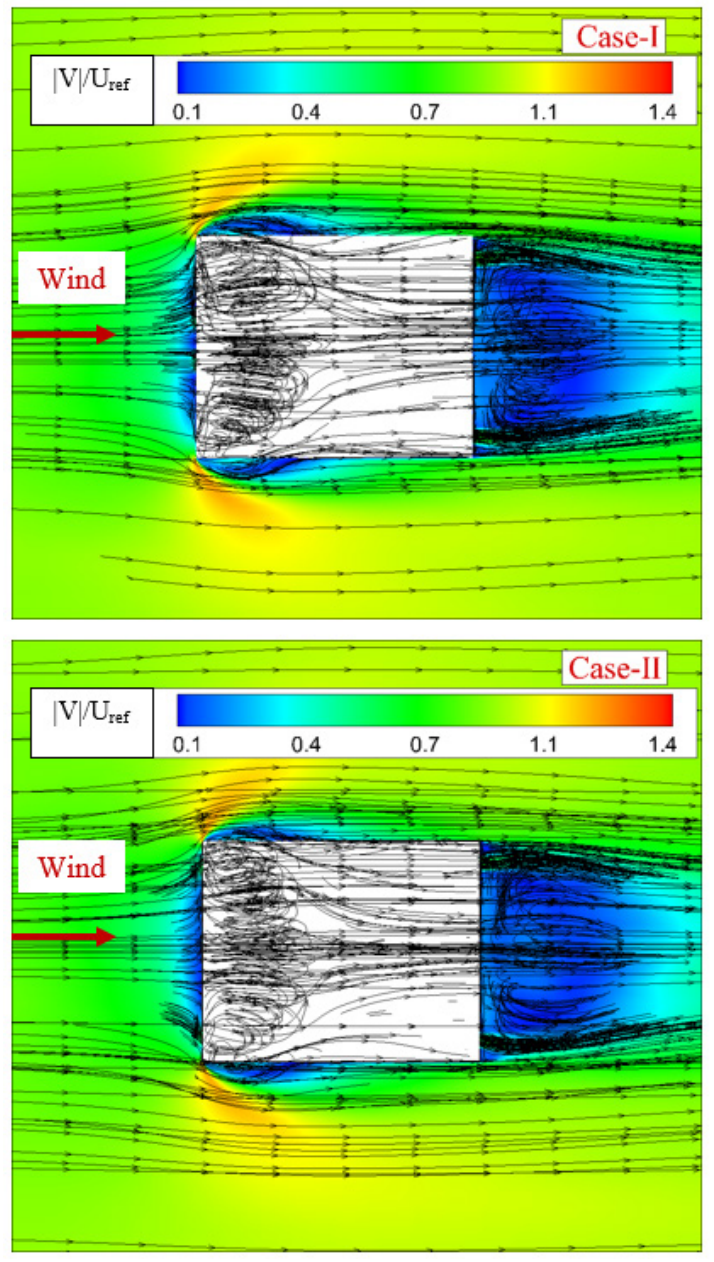

Fig. 11 

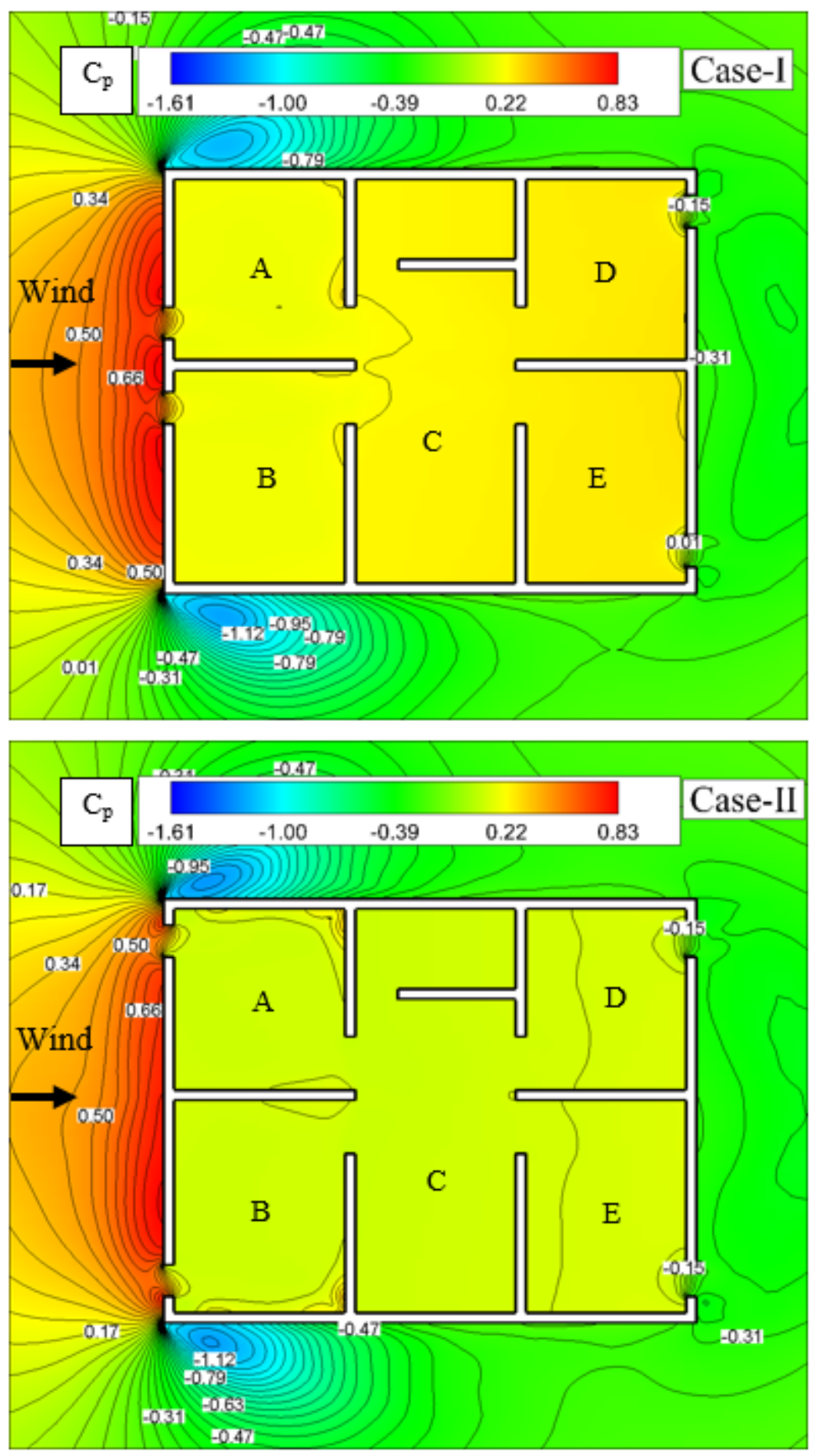

Fig. 12 

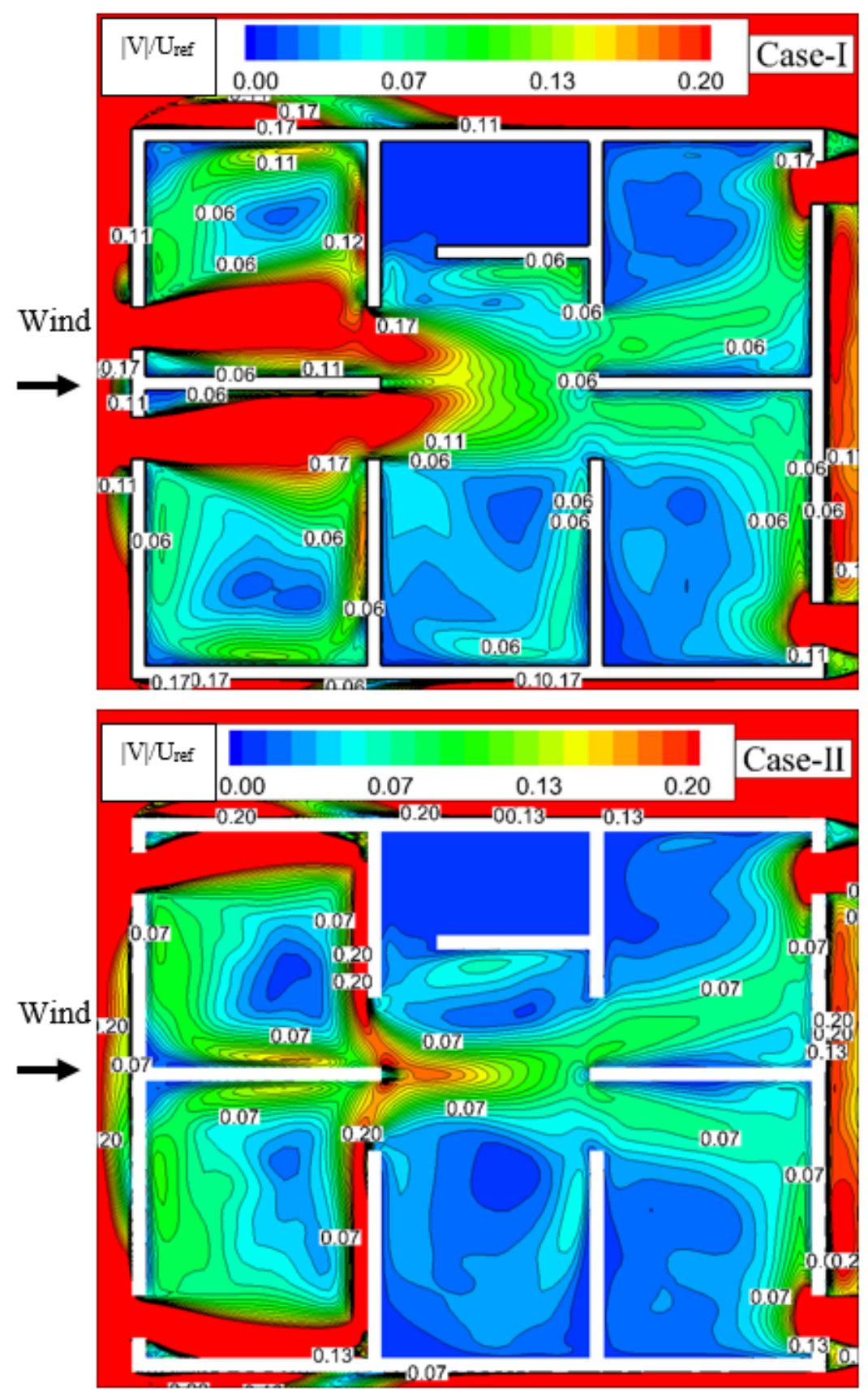

Fig. 13 


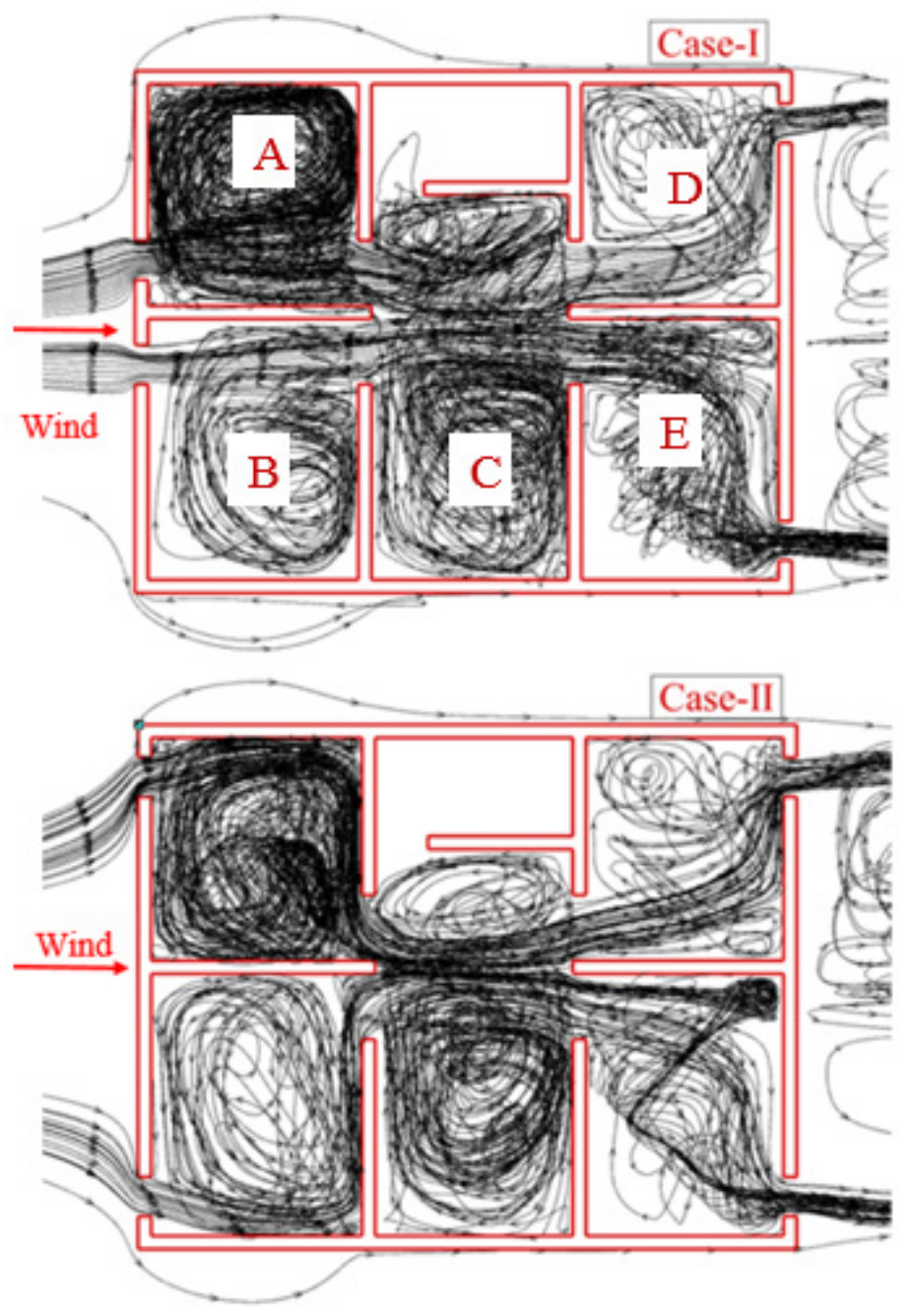

Fig. 14 

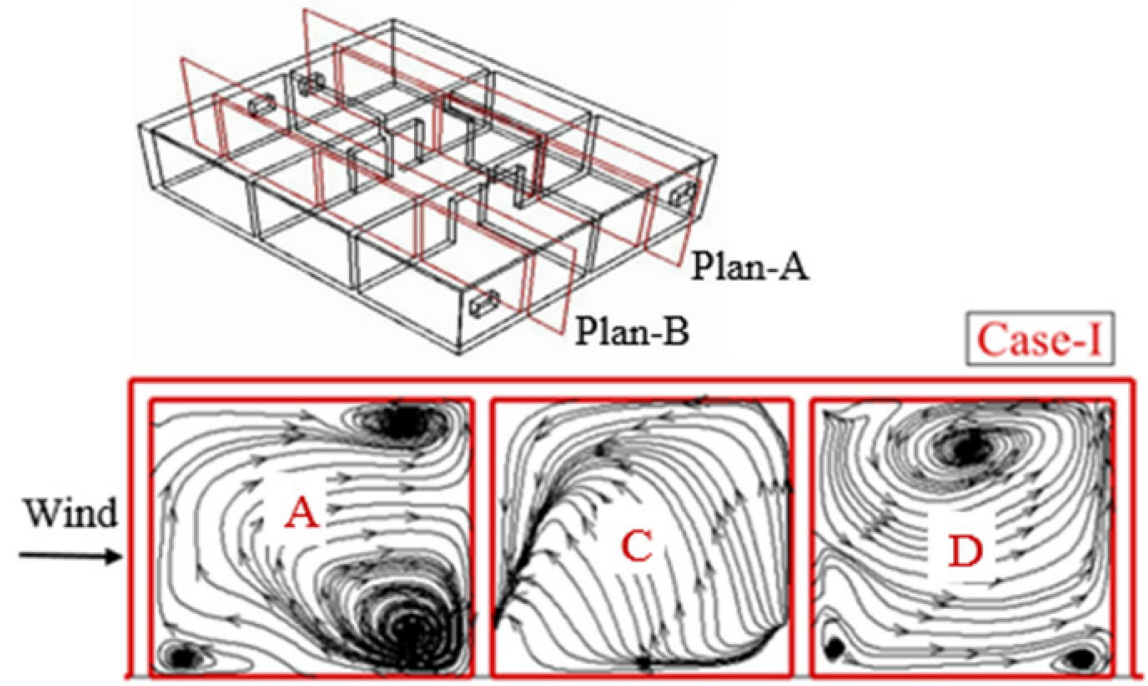

Case-I

a)
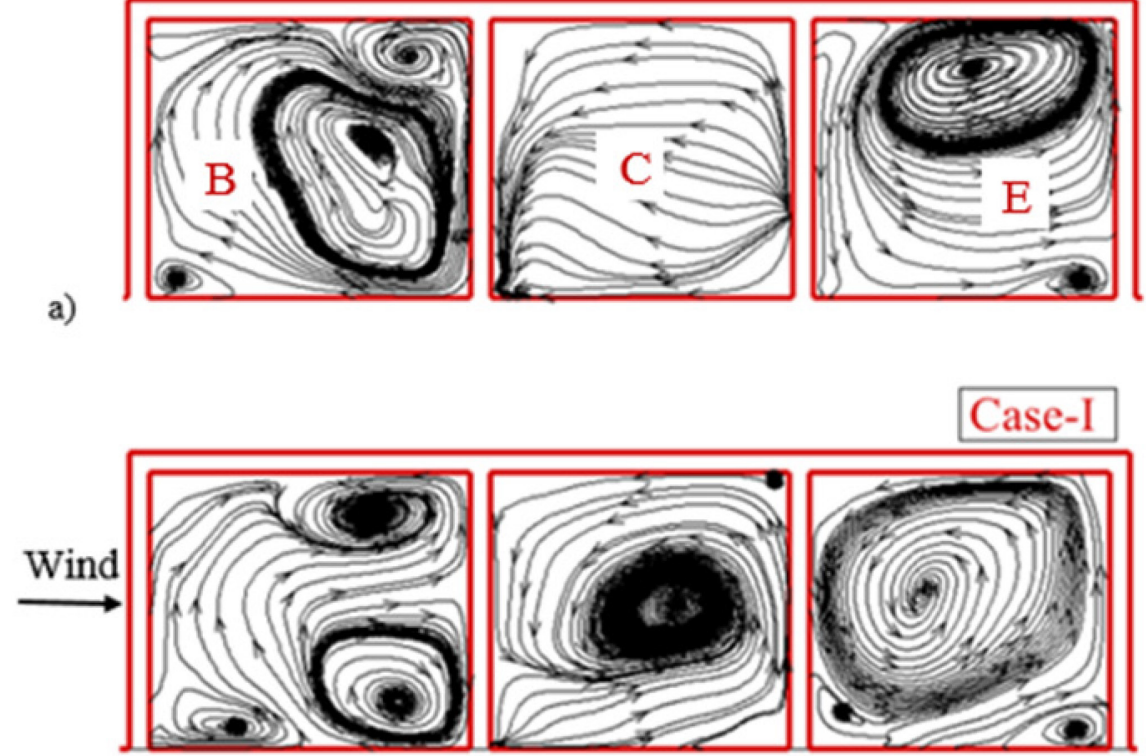

Case-II

b)

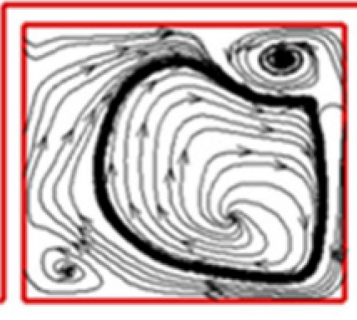

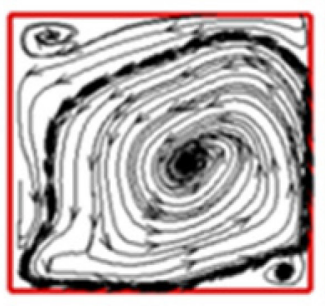

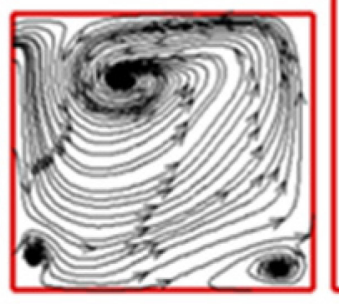

Fig. 15 

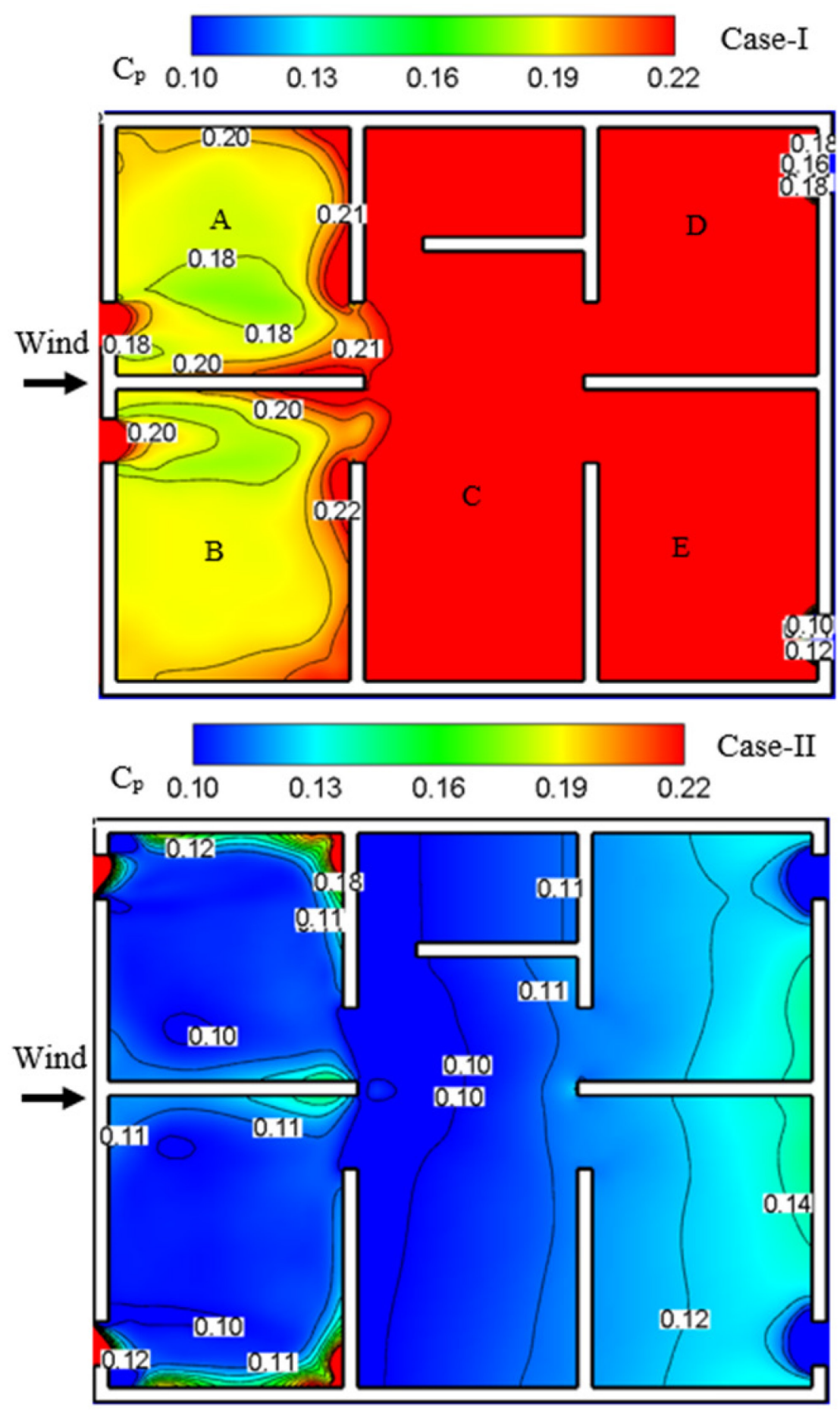

Fig. 16 


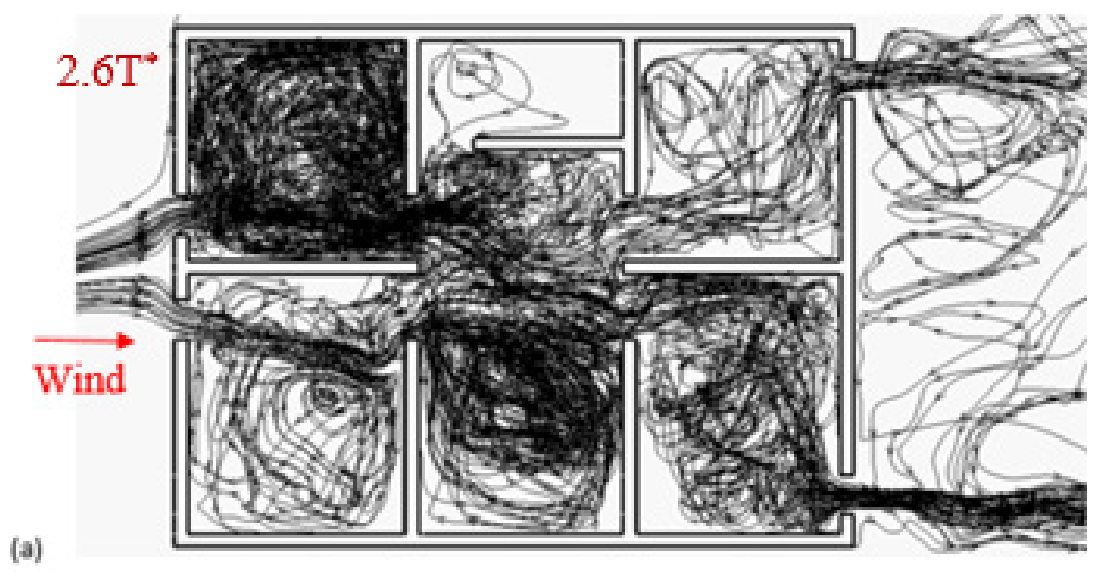

(b)
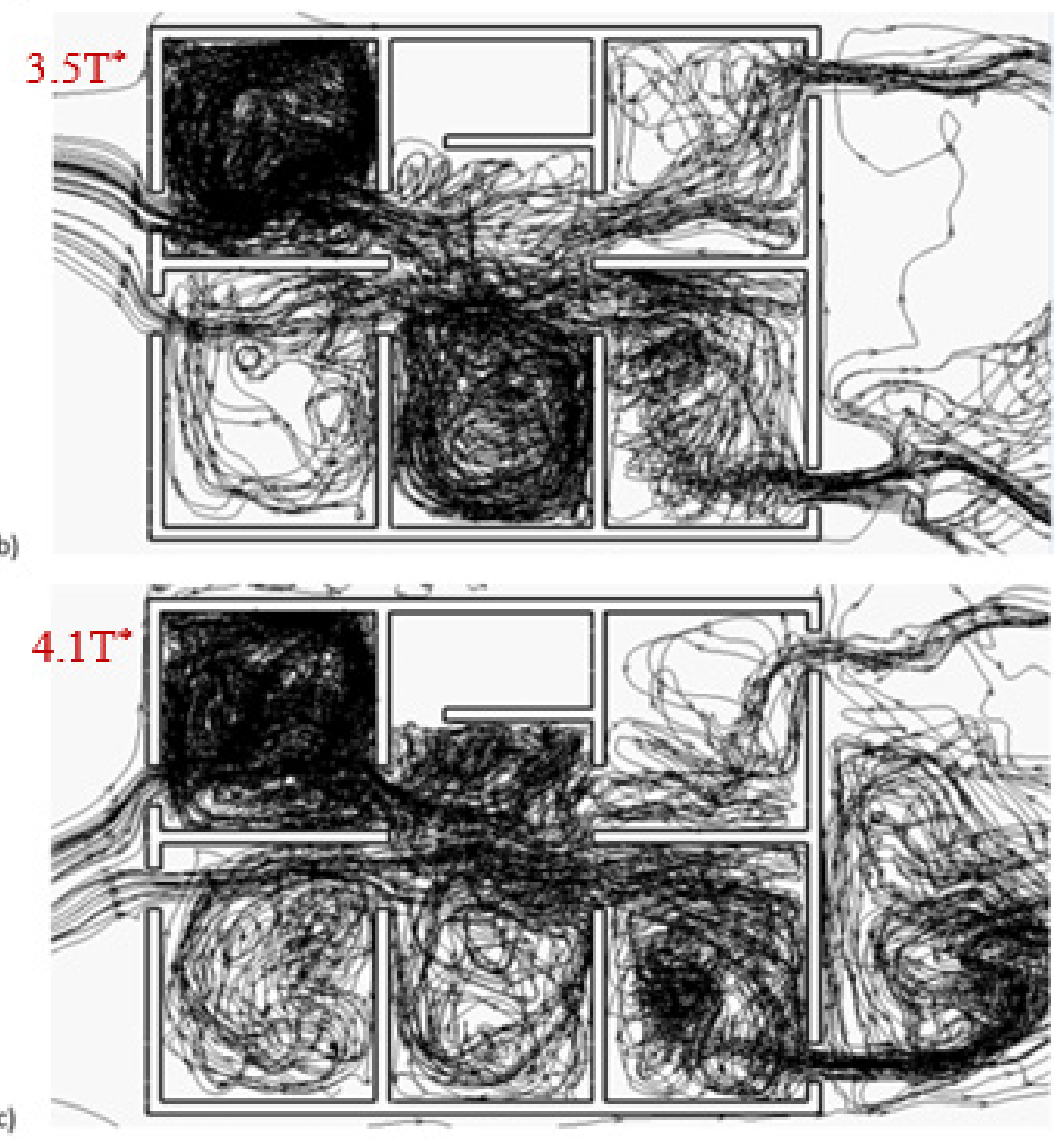

Fig. 17 


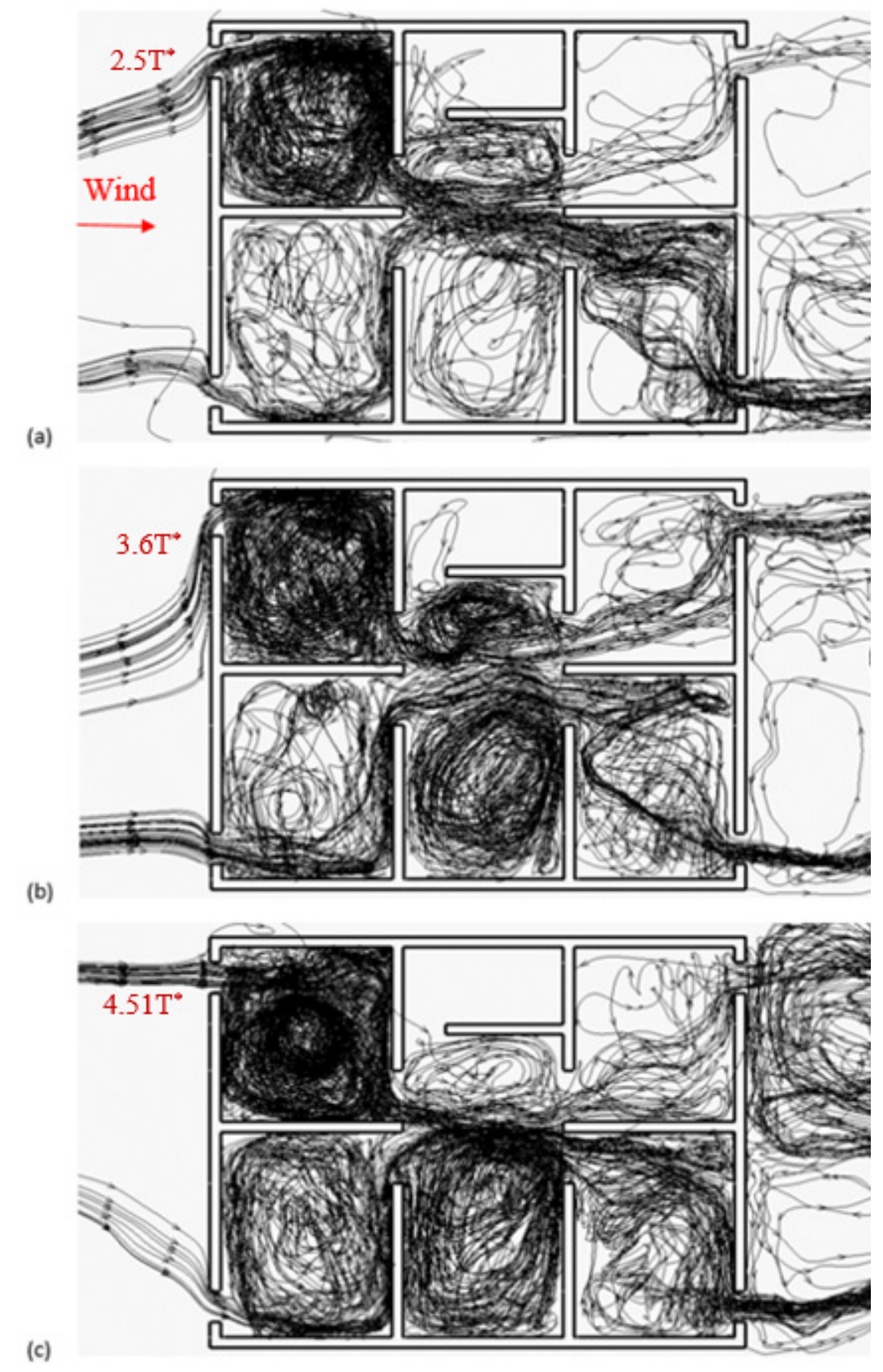

Fig. 18 


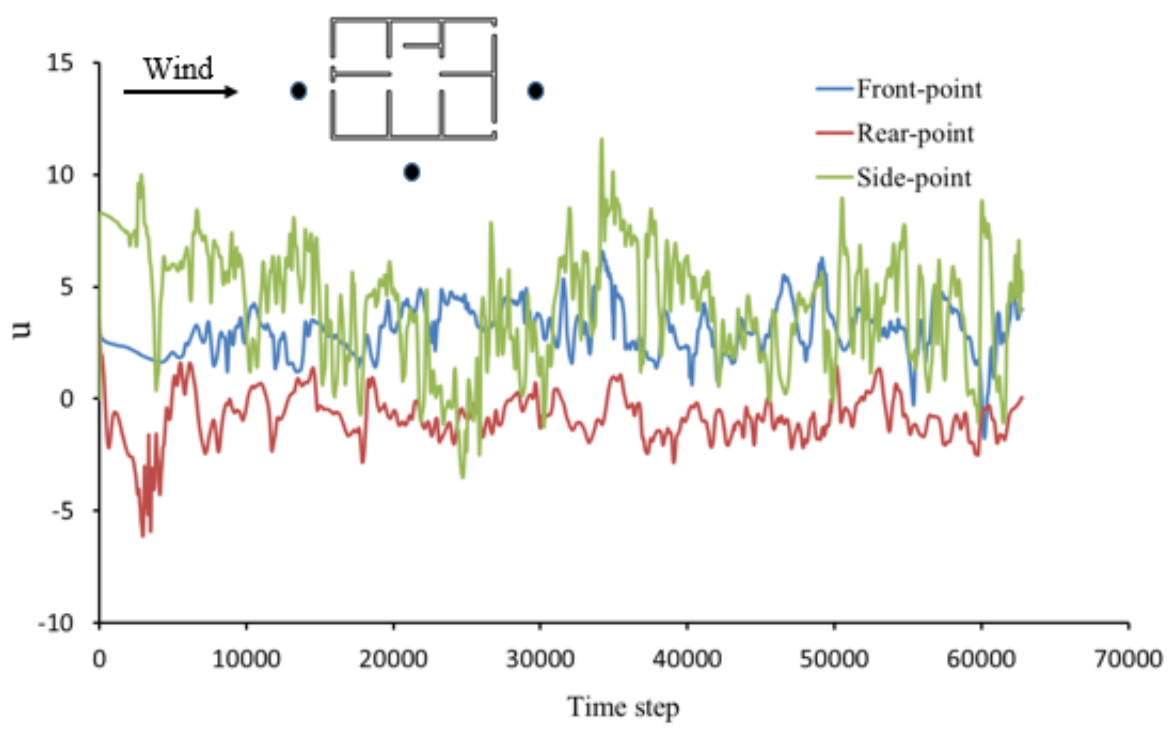

Fig. 19
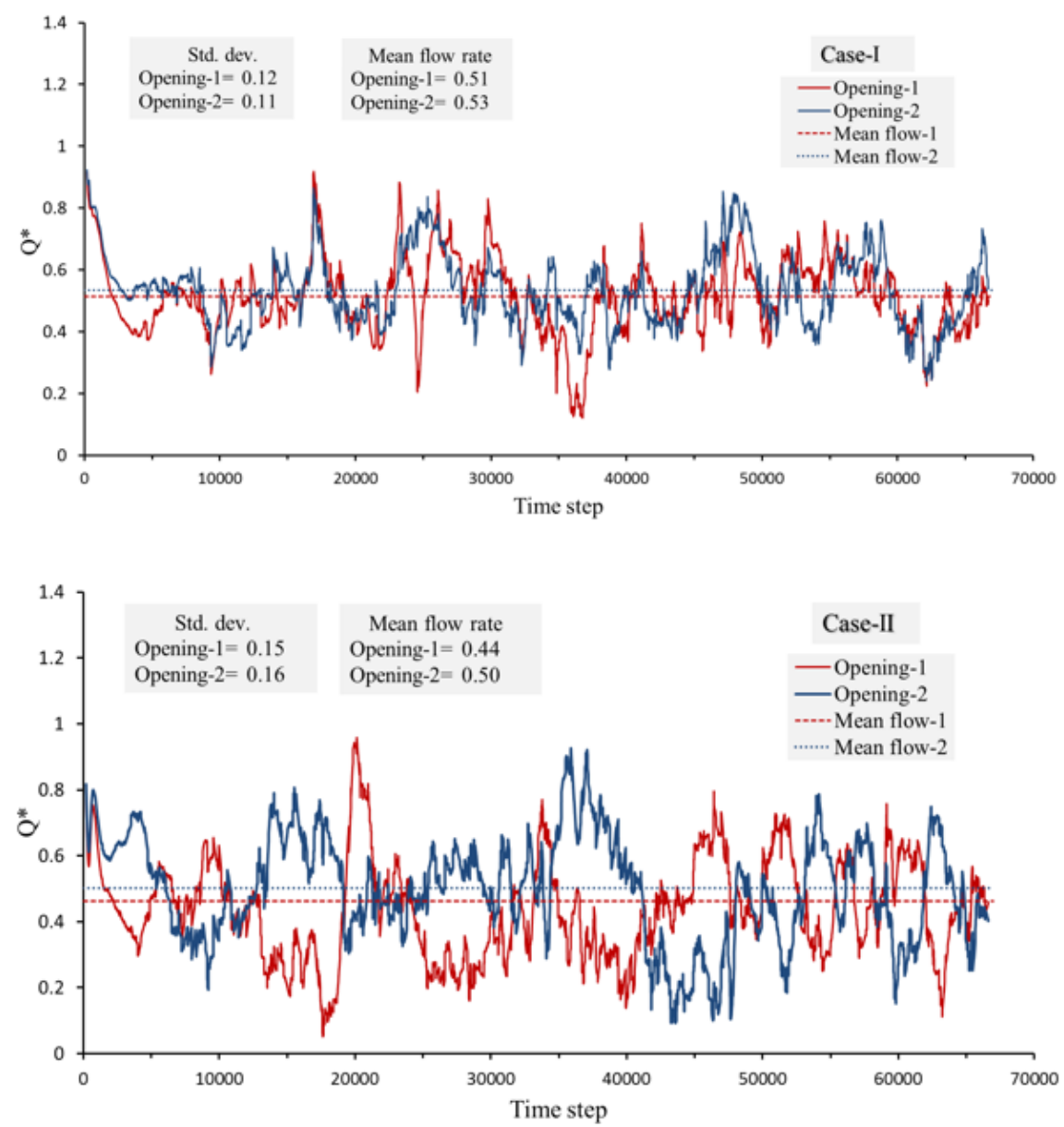

Fig. 20 


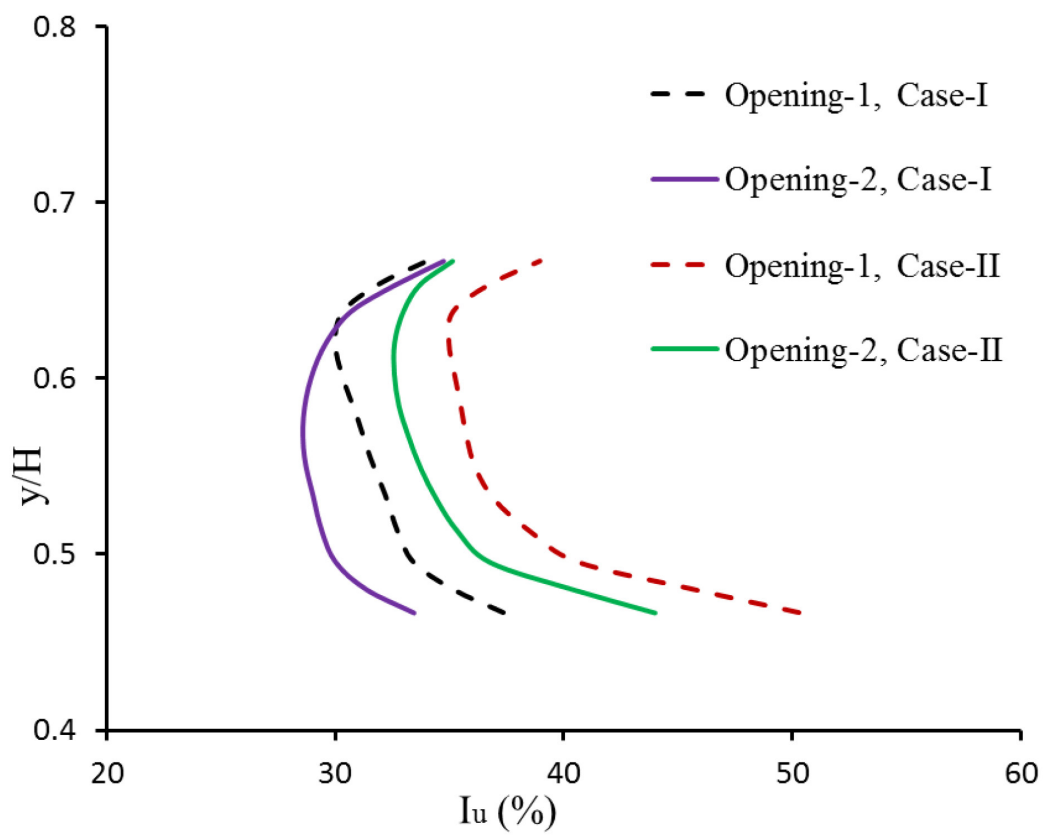

Fig. 21.

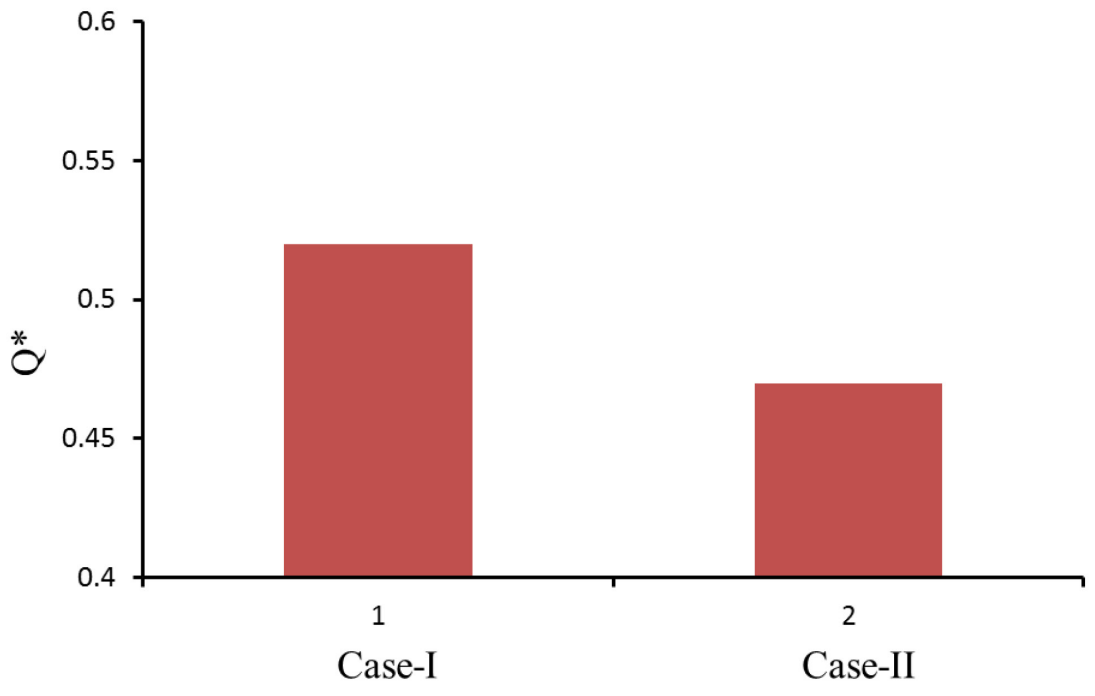

Fig. 22 

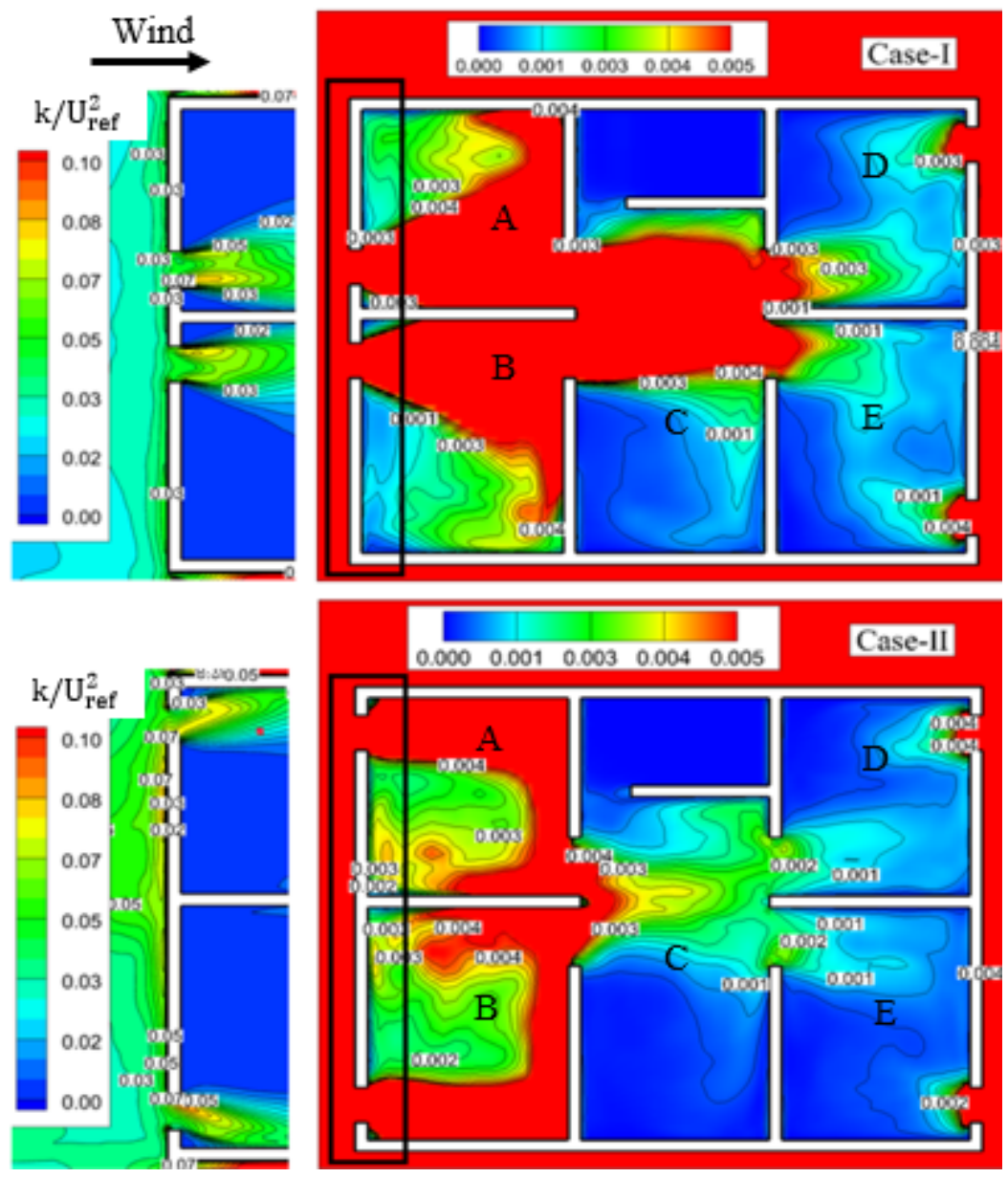

Fig. 23

Fig. 1. Layout of the building (dimension in metres).

Fig. 2. Geometry of the building models; (a) Perspective view and (b) Front view (dimension in metres).

Fig. 3. Geometry of the reduced-scale building model with dimensions (in metres) as studied by Ohba et al. [38]; (a) Perspective view and (b) Front view.

Fig. 4 Comparison of dimensionless mean velocity and turbulent kinetic energy profiles of the approaching wind with experimental results [38] at the inlet of the duct.

Fig. 5 Pressure coefficient comparison between LES and experimental results [38].

Fig. 6. The building inside a duct. 
Fig. 7. Computational domain and the mesh layout of grid (a) Side view and (b) Top view.

Fig. 8. Profiles of LES_IQ for Grid A and Grid B in the vertical lines for the Case-I.

Fig. 9. Power spectral density of the turbulent kinetic energy.

Fig. 10. Contours of dimensionless mean velocity magnitude $\left(|\mathrm{V}| / \mathrm{U}_{\text {ref }}\right)$ and streamlines around the building in the vertical centre-plane.

Fig. 11. Contours of dimensionless mean velocity magnitude $\left(\mid \mathrm{V} / / \mathrm{U}_{\text {ref }}\right)$ and streamlines around the building in the horizontal centre-plane.

Fig. 12 Contours of mean pressure coefficient $C_{p}$ around the building (horizontal plane $\mathrm{y} / \mathrm{H}=0.56$ ).

Fig. 13. Contours of dimensionless mean velocity magnitude $\left(|\mathrm{V}| / \mathrm{U}_{\text {ref }}\right)$ inside the building in the horizontal plane $(\mathrm{y} / \mathrm{H}=0.56)$.

Fig. 14. Mean streamlines velocity in the horizontal plane $(\mathrm{y} / \mathrm{H}=0.56)$.

Fig. 15. Mean streamlines velocity in the X-Y section in (a) Plane-A and (b) Plane-B.

Fig. 16 Contours of mean pressure coefficient $C_{p}$ inside the building (horizontal plane $\mathrm{y} / \mathrm{H}=0.56$ ).

Fig. 17. Instantaneous wind streamlines for Case-I in the horizontal plane $(\mathrm{y} / \mathrm{H}=0.56)$.

Fig. 18. Instantaneous wind streamlines for Case-II in the horizontal plane $(\mathrm{y} / \mathrm{H}=0.56)$.

Fig. 19. Time history of velocity, $\mathrm{u}$, at the monitoring points near the building.

Fig. 20. Variation of the dimensionless ventilation rate over time steps.

Fig. 21. Turbulence intensity in the centreline of openings.

Fig. 22. Comparison of dimensionless ventilation rates.

Fig. 23. Contours of dimensionless turbulent kinetic energy $\left(\mathrm{k} / \mathrm{U}^{2} \mathrm{ref}\right)$ in the horizontal plane. 